A 1500 990792

NBS

NBSIR 81-1643

A 11 106 979223

PUBLICATIONS

\title{
EFFICIENT COMPUTATION OF THE FAR FIELD RADIATED BY AN ARBITRARY RECTANGULAR- APERTURE DISTRIBUTION
}

\section{COMPUTER PROGRAM DOCUMENTATION}

Richard Lewis

Electromagnetic Fields Division

National Engineering Laboratory

National Bureau of Standards

Boulder, Colorado 80303

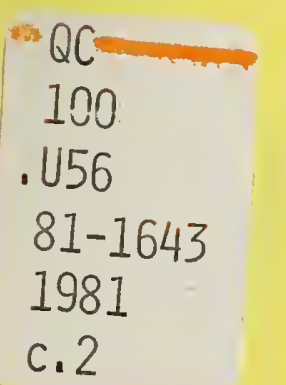

March 1981 


\section{EFFICIENT COMPUTATION OF THE FAR FIELD RADIATED BY AN ARBITRARY RECTANGULAR- APERTURE DISTRIBUTION}

\section{COMPUTER PROGRAM DOCUMENTATION}

Richard Lewis

Electromagnetic Fields Division National Engineering Laboratory National Bureau of Standards

Boulder, Colorado 80303

March 1981

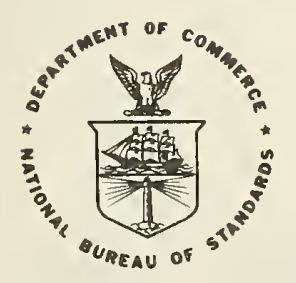

U.S. DEPARTMENT OF COMMERCE, Malcolm Baldrige, Secretary 
List of Figures........................................

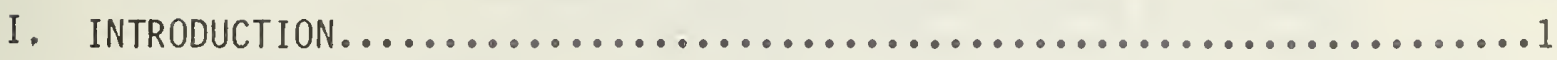

II. PROBLEM DESCRIPTION....................................

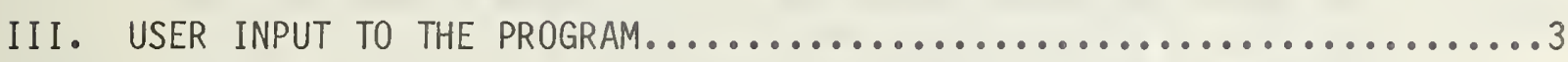

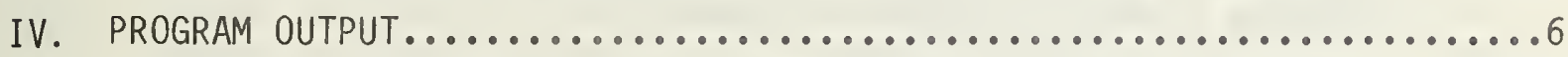

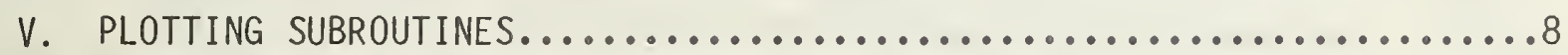

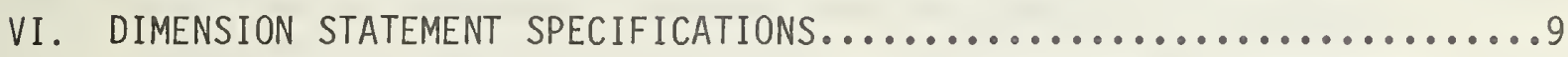

VII. PROGRAM VERIFICATION................................

APPENDIX A. Computation of the Far Field due to a Tangential Electric-Field Distribution over an Aperture Plane using Fast Fourier Transform

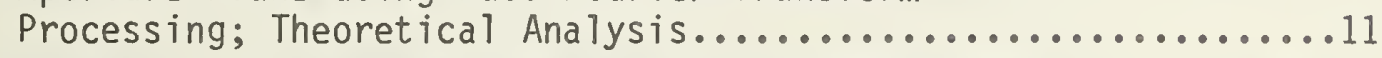
Appendix A.1 Far-Zone Electric-Field Components Expressed in Terms of Plane-Wave Spectrum Components.......................11

Appendix A.2 Finite Fourier Transform Representation of the Plane-Wave Spectrum Integral.............14

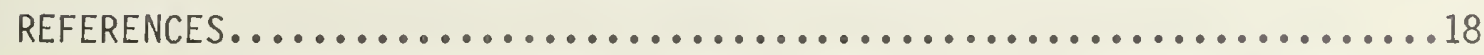

APPENDIX B............... Computer Program Listing for Computing Azimuth and Elevation Vector Components Along User-Specified

$X-$ and $Y-P l a n e$ Cuts in the Far Field Arising from a

Prescribed Rectangular-Aperture Field Distribution...........26

APPENDIX C............Computer Program Modifications to obtain Theta and Phi Vector-Component Output Instead of Azimuth and

Elevation Vector-Component Output.........................

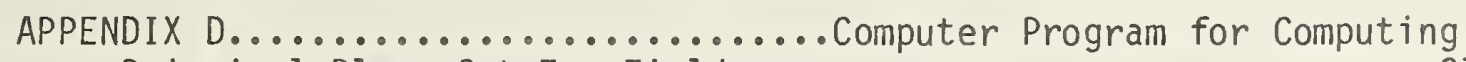

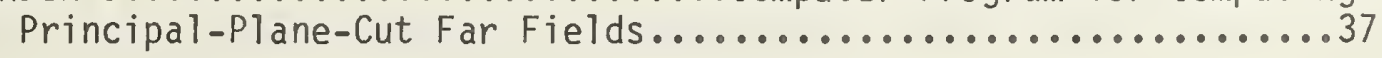

\section{LIST OF FIGURES}

Figure 1. Antenna coordinate system using $A$ and $E$ spherical angles with $y$ as the polar axis.................................

Figure 2. Antenna coordinate system using a and e spherical angles with $x$ as the polar axis..............................20 
Figure 3. Problem geometry, showing the rectangular aperture within an aperture $\mathrm{pl}$ ane and the far-zone position coordinates..........21

Figure 4. The principal plane cut $\phi=\frac{\pi}{2}$. PHI-component amplitude plot for a 5-wavelength-wide slit aperture (varied data-point-spacing increments)................22

Figure 5. The principal plane cut $\phi=\frac{\pi}{2}$. PHI-component amplitude plot for a 5-wavelength-wide slit aperture (varied Fourier integration ranges)..................23

Figure 6. Antenna pattern magnitude for a uniformiy excited circular aperture. $Y$-plane cut with constant elevation angle $E=10^{\circ} \ldots 24$

Figure 7. Antenna pattern magnitude for a uniformly excited circular aperture. $Y$-plane cut with constant elevation angle $E=30^{\circ} . .25$ 
Efficient Computation of the Far Field

Radiated by an Arbitrary Rectangular-Aperture Distribution

Computer Program Documentation

Richard Lewis

This report contains the computer documentation for calculating the far-zone electric field due to a user-prescribed electricfield distribution within a rectangular aperture. The far-field output is computed along two arbitrarily selected, perpendicular, spatial-frequency plane cuts. Program execution time is minimized by the use of fast Fourier transform (FFT) processing. The program was designed so that the required far-field output is obtained by processing only two, vector, one-dimensional FFTs. The far-field results are obtained in the form of elevation and azimuth vector components and electric-field-vector magnitude. A complete analytical discussion of the problem is presented, along with sample graphical output to illustrate how aliasing and output resolution limitations effect the graphical results.

Key words: Algorithm; antenna; aperture; computer program; electromagnetic; far-field; FFT; Fourier transform.

\section{INTRODUCTION}

This report constitutes the computer-program documentation for calculating the far-zone electric field, due to a prescribed electric-field distribution within a rectangular aperture, along two perpendicular spatialfrequency plane cuts. Program execution time is minimized by use of fast Fourier transform processing. The analytical basis for the computations is presented in Appendix A. The following text describes the computer program, listed in Appendix $B$, that has been developed for implementing these computations. The same nomenclature is used by the text as in the program listing for the variable parameters; consequently, reader familiarity with the input parameter list, as specified by the program comment cards, should prove beneficial.

\section{PROBLEM DESCRIPTION}

We divide space into two regions by an infinite plane surface (the aperture plane) containing the rectangular-aperture surface. The region in which the far-field computation is desired is assumed to be homogeneous and 
source free. The theoretical basis for calculating the far field due to a tangential electric-field distribution over an aperture plane is well known $[1,2,3]$. For physical antenna apertures that are large compared with a wavelength, the electromagnetic field amplitude will be small everywhere on the aperture plane except on the aperture surface. As a first approximation the far-zone radiation field may be found from the field on the aperture surface alone [1]. The aperture field may be determined either through direct near-field measurements or by suitable approximate analytical methods, such as ray tracing. It is presumed that the computer-program user can specify the tangential, aperture, electric-field vector (both amplitude and phase) at equidistant points on a rectangular grid over the aperture surface, while the field elsewhere on the aperture plane is assumed to be zero. The far-field output is obtained as a function of the spatial-frequency components $k_{x}$ and $k_{y}$. Here, we compute the far-field output along user-chosen $k_{x}$ - and $k_{y}$-plane cuts using fast Fourier transform (FFT) processing. We will refer to the $k_{x}=0$ and $k_{y}=0$ plane cuts as the principal-plane cuts. With just one $k_{x}$-plane cut and one $k_{y}$-plane cut far-field computation, the computer program herein described was designed so that the input data set would only be read in once while the far-field output would be obtained by just carrying out two vector one-dimensional FFTs. The result is an extremely efficient program, in terms of computation time and computer storage, for computing the far fields arising from a rectangular-grid aperture distribution along two perpendicular plane cuts.

The $x$-dimension of the rectangular aperture over which the user specifies the tangential electric-field vector is $a$; the $y$-dimension is $b$. The aperture plane is given by $z=0$, while the assumed aperture radiation travels in the positive z-direction. The number of data points within the aperture along the $x$-direction is NX, while the number of data points along the $y$-direction is NY. Let us presume that a matrix of $x$-component data and a matrix of $y$-component data is available for specifying the aperture field, and that each component value at a given data point is specified as a complex number.

$$
|E| e^{i \psi}=|E| \cos \psi+i|E| \sin \psi
$$

$|E|$ being the amplitude and $\psi$ being the phase of a particular datum. The dimensions of these two vector-component matrices would each be given by 
$N Y \times N X$, so that each matrix row corresponds to a constant value of the $y$-coordinate, while each matrix column corresponds to a constant value of the $x$-coordinate. Thus, the row index $r$ of the data matrix is proportional to the $y$-coordinate, while the column index $c$ of the data matrix is proportional to the $x$-coordinate. For each row or column, a data point at the center of the respective $x$-dimension or $y$-dimension of the aperture shall be specified, along with an equal number of data points on each side of the midpoint. Consequently, NX and NY are both odd numbers. The spacing between adjacent data points in the $x$-direction is $\delta_{X}=a / N X$, while the spacing in the $y$-direction is $\delta_{y}=b / N Y$. It is presumed, by these equalities, that the edges of the rectangular aperture are located half a data-point spacing beyond the farthest data points within the aperture.

\section{USER INPUT TO THE PROGRAM}

The program user provides a subroutine, GETARAY, that obtains or calculates one row of $x$-coordinate aperture-field data, corresponding to a particular value of the $y$-coordinate and to a particular vector component, each time it is called. The subroutine arguments are NX and STOR, where NX is the number of data points in the row and STOR is a complex array of dimension NX for storing the aperture-field data. The value of NX may not be changed by the user's subroutine, GETARAY. This subroutine is called NY times for the $x$-component data, followed by another NY times for the $y$-component data. Each successive call represents a lower row (greater row-index number) in the data matrix of each vector component, or a larger value of the y-coordinate. Within the row of data supplied by GETARAY, each successive datum represents a larger value of the $x$-coordinate. In those regions of the rectangular aperture that are beyond the boundary of the user's physical aperture, the user is expected to provide zero-fill via subroutine GETARAY.

It may be observed that spatial integration of a physical electric field over the aperture plane will give rise to a function of spatial frequency $k_{x}$ and $k_{y}$ that is virtually bandlimited [2]. According to the sampling theorem [4], a band-limited two-dimensional function with bandlimits $k_{x}$ and $k_{y}$ may be completely recovered using sampling intervals $\delta_{x}$ and $\delta_{y}$ that satisfy the relations, 


$$
k_{x}=\frac{\pi}{\delta_{x}} \text { and } k_{y}=\frac{\pi}{\delta_{y}} \text {. }
$$

A virtual bandlimit only slightly greater than the spatial propagation constant $k=2 \pi / \lambda$ ordinarily prevails, where $\lambda$ is the wavelength in the medium, so that an aperture data-point spacing of $\delta_{x} \simeq \delta_{y} \leqslant \lambda / 2$ generally is adequate. However, in order to minimize aliasing errors in the far-sidelobe region, closer data-point spacings may be required (cf. Appendix A, eq. (16) and the preceding discussion, for analytical details.) Consequentiy, computer-program flexibility is maintained with the specification

$$
\delta_{x} \equiv \frac{\lambda}{S_{x}} \text { and } \delta_{y} \equiv \frac{\lambda}{S_{y}} \text {. }
$$

Here, $S_{X} \simeq S X$ and $S_{Y} \simeq S Y$, where $S X$ and $S Y$ are dimensionless numbers specified by the program user. There is only a small difference between $S_{X}$ and $S X$ and between $S_{y}$ and $S Y$, which the computer program can automatically compute. Thus, the user need only be concerned with the order of magnitude of SX and SY. With a uniformly-excited-aperture test case, highly accurate comparisons with theoretical results required values of $S X, S Y>9$ due to the presence of evanescent modes. If evanescent modes are not present, values of $S X, S Y \simeq 2$ should suffice for most applications. Values of $S X, S Y<2$ should be used cautiously. In addition to $S X$ and $S Y$, the user must specify the variables ALPHA $=\alpha$ and BETA $=\beta$, where $\alpha$ and $\beta$ serve to specify the aperture dimensions normalized to the wavelength. Thus,

$$
\alpha \equiv \frac{a}{\lambda} \quad \text { and } \quad \beta \equiv \frac{b}{\lambda} \text {. }
$$

As a consequence of these definitions, the values of the aperture-spacing normalization constants, $S_{x}$ and $S_{y}$, are given by

$$
S_{X}=\frac{N X}{\alpha} \text { and } S_{y}=\frac{N Y}{\beta} \text {. }
$$

In practice, the computer program makes the initial computations, $N X=\alpha \star S X$ and $N Y=\beta * S Y$, and then checks to see if the values of $N X$ and $N Y$ so computed are odd. If not, then unity is added to the result so that the final values of NX and NY will be odd. Then, the exact values of $S_{X}$ and $S_{y}$ are computed. Although only the field within the aperture region will contribute to the 
integrand, with FFT processing the resolution of the far-field output will depend on the size of the area of integration. As an example, if a uniform aperture excitation is specified, and if the area of integration just equals the aperture area, then the program would produce far-field output at the points $k_{x}=0, \pm 2 \pi / a, \pm 4 \pi / a, \pm 6 \pi / a$, etc., corresponding to the exact (elevation-plane) far-field pattern function,

$$
E \propto \frac{\sin \left(k_{x} \frac{a}{2}\right)}{k_{x} \frac{a}{2}} .
$$

In other words, except for one point, one would just obtain output values at the nulls of the far-field pattern function, which would provide extremely limited information. A more detailed picture would be obtained by increasing the output resolution so as to produce output values at intermediate points between the pattern-function nulls. By extending the area of integration and adding zero-fill to the FFT data input, one can increase the output resolution.

The extent of the area of integration is increased by increasing the number of data points supplied to the FFT processing routine. The data amplitude values at each additional data point are automatically set equal to zero by the computer program. The number of data points supplied to the FFT processor is designated NNX in the case of $x$-direction FFT processing and NNY in the case of $y$-direction FFT processing, where NNX > NX and NNY > NY. In the case of the FFT processor used by the computer program, the number of input data points must equal a power of two. Thus, NNX $=2^{* * M M X}$ and NNY $=2 * * M M Y$. The program automatically chooses NNX to be twice the largest power of two that is just greater than NX, and similarly for NNY and NY. However, these automatically generated values may not suffice for all applications; consequently, the automatically generated values of NNX and NNY

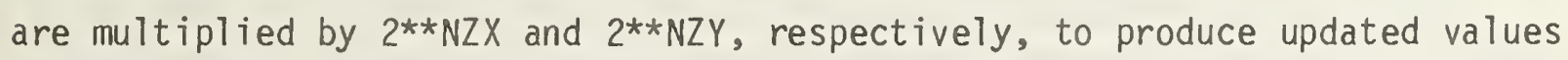
of NNX and NNY. The two constants NZX and NZY are specified by the user, where $N Z X, N Z Y \geq-1$. The recommended specification is $N Z X=N Z Y=1$ or greater, although specifying NZX or NZY equal to zero may be adequate if the aperture field tapers to near zero at the aperture boundaries. With a uniformlyexcited-aperture test case, the values $N Z X=N Z Y=2$ gave smooth plotting resolution with a microfilm plotter subroutine. It is not recommended that 
the -1 specification for NZX or NZY be used unless NX or NY is just slightly larger than some power of 2, as otherwise there will not be adequate zero-fill added to the input data. It should be recognized that the larger that NNX and NNY become, the Jonger the FFT computation time becomes and the larger the computer-storage requirement becomes.

In addition to the input variables already described, the user must specify the azimuth angle $A_{0}$ and the elevation angle $E_{0}$ corresponding to the particular plane cuts desired. These input quantities are best discussed within the context of the next section.

\section{PROGRAM OUTPUT}

The program computes the azimuth $\left(E_{A}\right)$ and elevation $\left(E_{E}\right)$ vectorcomponents of the far field, along with the antenna pattern or electric-vector magnitude (the program listing for azimuth and elevation vector-component output is as given in appendix B, while a listing of substitute cards for use when theta and phi vector-component output is preferred may be found in appendix $\mathrm{C})$. The program computes both output vector components along a constant $k_{x}$-coordinate $p l a n e$ cut and along a constant $k_{y}$-coordinate plane cut as respective functions of elevation (e) and azimuth (A). That is, the spatial-frequency component that is not held constant becomes the sole output. function variable. Note that both the elevation (e) and azimuth (A) angles become equal to the polar angle theta in the event that principal-plane cuts are selected (users who only require principal-plane-cut computations may wish to utilize the simpler version of the program given in appendix D). The relationships between the various spherical-coordinate-system angles that have been mentioned are shown in figures 1 and 2, with supplementary discussion found in $[5]^{\dagger}$.

At this point it would be appropriate to note that the final compured values of the far-zone electric fieids are renormalized, such that the factor

the notation used here to designate the alternative azimuth and elevation angles is "a" and "e", whereas in [5] these alternative angles are designated $\alpha$ and $\beta$. The notation $A$ and $E$ normally is used with az/el antenna mounts, while the a and e designations apply to el/az antenna mounts. Our $A$ and $E$ angle designations agree with the notation used in [5] for these quantities. 
$\frac{\lambda}{r} e^{i k r}$ is divided out.

Corresponding to each start-up of the program, a complete set of input $x$-component and $y$-component aperture data is requested from GETARAY by the program, and one $k_{x}$-plane cut and one $k_{y}$-plane cut far-field computation is carried out. The particular $k_{x}$-plane cut generated is selected by specifying the azimuthal angle $A_{0}$, at an elevation angle of zero degrees, that corresponds to the particular value of $k_{x}$ desired. Similarly, the particular $k_{y}-p l a n e$ cut generated is selected by specifying the elevation angle $E_{0}$ corresponding to the particular value of $k_{y}$ desired (the "o" subscripts are used here to distinguish the user-specified azimuth and elevation angles that define the plane cuts, whereas the omission of this subscript implies the general angular-coordinate variables). The relationships between the farfield spatial-frequency variables, $k_{x}$ and $k_{y}$, and the spherical-coordinate angles, depicted in figures 1 and 2 , are given by,

$$
\begin{aligned}
& k_{x}=k \cos E \sin A=k \sin \theta \cos \phi=k \sin a \\
& k_{y}=k \sin E=k \sin \theta \sin \phi=k \cos a \sin e
\end{aligned}
$$

From the preceding, we see that the desired $k_{x}$ - and $k_{y}$-plane cuts are given by $k_{x} / k=\sin A_{0}$ and $k_{y} / k=\sin E_{0}$, respectively, where the angles $A_{0}$ and $E_{0}$ are specified by the user.

Upon completing the far-field computations, the azimuth and elevation vector-components and the antenna pattern are plotted as a function of elevation (e) and azimuth (A), respectively, for the $k_{x}$-plane cut and the $k_{y}-p l a n e$ cut. The plotting is limited to angles in the visible range (i.e., real angles within the spherical spatial-frequency region of radius $k$, such that $k_{z}=\sqrt{k^{2}-k_{x}^{2}-k_{y}^{2}}$ is real). This visible range not only excludes complex evanescent angles, but also limits the range on $k_{y}$ and $k_{x}$ to $k_{y} \leq k \operatorname{Cos} A_{0}$ and $k_{x} \leq k \operatorname{Cos} E_{0}$, respectively, in the case of the $k_{x}$ - and $k_{y}-p l a n e$ cuts. Since the $k_{x}-p l a n e$ cut is plotted versus elevation (e), while the $k_{y}$-plane cut is plotted versus azimuth $(A)$, one obtains a full $\pm 90^{\circ}$ plotting range. However, it must be recognized that rapid variations, as respective functions of $k_{y}$ or $k_{x}$, will appear greatly expanded when $A_{0}$ or $E_{0}$ do not equal zero. 


\section{PLOTTING SUBROUTINES}

The subroutine PAMPLOT that is supplied with the program for setting up the plotting arrays permits the user to restrict the plotting range through the specification of maximum and minimum abscissa values. Both relative amplitude in $\mathrm{dB}$ and phase in degrees are plotted for each vector-component, with just relative amplitude in $\mathrm{dB}$ plotted for the antenna pattern. This routine labels each plot with the peak amplitude level in $\mathrm{dBL}^{\dagger}$ and with a self-generated caption that automatically indicates the vector-component plotted; phase, amplitude, or magnitude plot; and the value of either the azimuthal angle $\left(A_{0}\right)$ or the elevation angle $\left(E_{0}\right)$ corresponding to the particular $k_{x}$ - or $k_{y}$-plane cut that has been generated. Also, a userspecified 40-character graph legend is placed on each plot. In addition to plotting far-field output, subroutine PAMPLOT allows the user to obtain a printout of every $j$ th data point, $j=1,2, \ldots$, etc. (Note that the reciprocal of $j$ times 100 gives the percentage of output points to be printed.) If $j=0$, printout is suppressed. This printout gives the abscissa point, absolute amplitude, and phase in degrees.

The actual plotting routine supplied with the program is limited to point plotting on the user's printout. The user can elect either to point-plot the amplitude and phase of each vector component separately, or else the amplitude and phase curves can both be point-plotted on the same graph. The latter plotting mode has the advantage of placing two closely related curves in proximity to each other. The disadvantage is that ordinate-axis labeling of the phase plot will be suppressed by ordinate-axis labeling of the amplitude plot. A microfilm plotting routine is highly desirable. Subroutine PAMPLOT contains an illustrative calling statement to the dummy routine CRTPLOT, which may be replaced by the user's own plotting-routine call. The dummy subroutine that is called here is SUBROUTINE CRTPLOT (XARRAY, YARRAY, XMAX, XMIN, YMAX, YMIN, N, LABEL, NO, NOMAX), where XARRAY contains the $N$ abscissa points, YARRAY contains the $\mathrm{N}$ ordinate points, XMAX is the greatest abscissa value plotted, XMIN is the least abscissa value, YMAX is the greatest ordinate

H Here, dBL is taken to mean $20 \log _{10}(E)$, where $E$ designates the quantity whose amplitude level is desired. (cf. IEEE Standard Dictionary of Electrical \& Electronics Terms under "level".) 
value, YMIN is the least ordinate value, $N$ equals the number of data points per curve, LABEL is a nine-word graph legend, NO is the number of the curve being plotted, and NOMAX is the number of curves per graph ( $1 \leq$ NO $\leq$ NOMAX $\leq 2)$.

\section{DIMENSION STATEMENT SPECIFICATIONS}

The program comment cards supplied with each routine should enable the user to specify the correct input to run the program. Particular attention is called to the array-dimension specifications in the main program. Insufficient dimensions (as specified by the user's data statement) will cause the program to abort. Note that the dimensions of arrays THETA and DATA are based on the final computed value of NNX, while the dimension of array EI equals twice the sum of the final computed values of NNX and NNY. The dimensions of arrays EXPX and STOR are equal to NX, while the dimension of array EXPY is equal to NY.

\section{PROGRAM VERIFICATION}

In order to verify that the computer program was working properly, it was tested to see how accurately it could compute the far fields of uniformly excited apertures, for which exact formulas are available [7, pp. 332-336]. Good agreement was obtained between the theoretical results and the computer program output, particularly as the data-sampling interval was decreased. As mentioned earlier, very short data-point spacings were required due to the presence of evanescent modes in these hypothetical aperture distributions. Tests were carried out both for a rectangular aperture and for a circular aperture with zero fill to the boundary of the enclosing square aperture. In order to facilitate numerical comparisons, computations with the exact formulas were carried out at the same far-field coordinates that the computer program used to calculate the far-zone fields.

In figure 4 we show some principal-plane-cut results for a uniformlyilluminated slit aperture five wavelengths wide, in which we compare results from computations with a data-point spacing of $\lambda / 5$ and $\lambda / 3$ to the corresponding exact theoretical curve. The solid-line curve in figure 4 corresponds to the $\lambda / 5$ data-point spacing curve, while the dots and crosses, respectively, correspond to the theoretical curve and to the $\lambda / 3$ data-point 
spacing curve. Just those portions of the latter two curves which do not overlap the solid line curve are shown in the figure. Thus, the only differences shown are in the far side-lobe region where the overlapping ends of the replicated far-field function contribute the most to the aliasing error (refer to Appendix A, eq. (15) for analytical details). As may be anticipated from this figure, we have verified that the computed curve does get closer and closer to the theoretical curve as the data-point spacing gets smaller and smaller.

To illustrate the effect of adding zero fill to the FFT to increase the output resolution, in figure 5 we show a comparison between two curves having the same data-point spacing but different specified values of NZY. Here, the solid line curve corresponds to NZY $=0$ while the dotted line curve corresponds to $N Z Y=3$. Adjacent points on each curve are connected by a straight line with no curve fitting between points. Both figures 4 and 5 correspond to the same plane cut and the same aperture excitation, but the solid line curve of figure 4 was generated with $N Z Y=4$; consequently, the nulls shown in figure 4 are uniformly deeper than the nulls shown in the dotted line curve of figure 5. However, the computed values of figure 5 are the more accurate, as they were obtained using a data point spacing of $\lambda / 7$.

Finally, in figures 6 and 7 we show some antenna pattern magnitudes for a uniformly excited circular aperture three wavelengths in diameter. Here, we were interested in comparing the computer program output against the theoretical model for some arbitrarly selected plane cuts. Consequently, we show two $k_{y}$-plane-cut antenna-pattern curves plotted versus azimuth, in figures 6 and 7, corresponding respectively to a $10^{\circ}$ elevation angle and a $30^{\circ}$ elevation angle. The peak amplitude in figure 7, incidently, is about $15 \mathrm{~dB}$ below the peak amplitude in figure 6. In order to achieve highiy accurate program output, a data point spacing of $\frac{\lambda}{21}$ was used, which resulted in the generation of numerical $d B$ values for the furthest side lobes that agreed with the theoretical results within eight-tenths of one percent. This compares to just five or ten percent agreement between the furthest side lobes of the theoretical model and the far side lobes of the computed curves plotted in figure 4. A value of $N Z X=N Z Y=2$ was selected for our circular aperture computations, resulting in just moderately smooth plotting resolution. It might be remarked that the aperture excitation was assumed to be diagonal to the cartesian coordinates of the aperture, resulting in the asymetrical $k_{y^{-}}$ plane-cut patterns shown. 
Computation of the Far Field due to a Tangential Electric-Field Distribution over an Aperture Plane using Fast Fourier Transform Processing; Theoretical Analysis

\section{A.1 Far-Zone Electric-Field Components Expressed in Terms of Plane-Wave Spectrum Components}

An expression for the far-zone electric-field vector transverse to the z-direction is readily obtained by integrating the near-zone tangential field over an aperture plane [1], [2]. Thus, we have the far-zone electric field transverse to the z-direction expressed as

$$
\underline{E}_{t}(\underline{r}) \sim \frac{-i k \cos \theta}{2 \pi} \frac{e^{i k r}}{r} \underline{B}\left(\frac{k}{r} \underline{R}\right)
$$

where the aperture-plane integral is defined as

$$
\underline{B}\left(\frac{k}{r} \underline{R}\right)=\int_{-\infty}^{\infty} \int_{-\infty}^{\infty} \underline{E}_{t}\left(\underline{P}^{\prime}\right) e^{-i \frac{k}{r} \underline{R} \cdot \underline{P}^{\prime}} d x^{\prime} d y^{\prime} .
$$

Here, $\underline{p}^{\prime}=x^{\prime} \underline{a}_{x^{\prime}}+y^{\prime} \underline{a}_{y^{\prime}}$ and $\underline{R}=\underline{x}_{x}+\underline{y} \underline{a} y$, where $\underline{a}_{x}=\underline{a}_{x^{\prime}}$ and $\underline{a}_{y}=\underline{a}_{y^{\prime}}$ are unit vectors along the $x$ and $y$ coordinate-system axes, and where $x$ and $y$ denote far-zone position coordinates while $x^{\prime}$ and $y^{\prime}$ denote aperture-plane position coordinates. The far-zone radial coordinate is $r=\sqrt{x^{2}+y^{2}+z^{2}}$. These geometrical relationships are depicted in figure 3 . The propagation constant is $k=2 \pi / \lambda$, where $\lambda$ is the wavelength. An $e^{-i \omega t}$ time dependence is implicitly assumed by (1); thus $k=\frac{\omega}{c}$ where $c$ is the velocity of light. The spatial-frequency components $k_{x}$ and $k_{y}$ are related to the far-zone position coordinates by the relations, $k_{x}=k \frac{x}{r}$ and $k_{y}=k \frac{y}{r} . \quad E_{t}\left(P^{\prime}\right)$ is the tangential electric-field vector in the aperture plane. The z-component of the far-zone electric field is also required, but it can be obtained from the expression

$$
B_{z}\left(\frac{k}{r} \underline{R}\right)=-\frac{1}{r \cos \theta} \underline{R} \cdot \underline{B}\left(\frac{k}{r} \underline{R}\right) \text {, }
$$

which results from the fact that each plane-wave spectrum vector, $\underline{B}\left(\frac{k}{r} \underline{R}\right)+\underline{a}_{z} B\left(\frac{k}{r} \underline{R}\right)$, must be orthogonal to the corresponding propagation 
direction $\underline{k}=\frac{k}{r}\left(\underline{R}+\underline{z a}_{z}\right)$.

Consequently, it readily follows from (1) and (3) that the theta and phi components of the far field can be expressed as [1]

$$
\begin{aligned}
& E_{\theta}(\underline{r}) \sim-\frac{i k}{2 \pi} \frac{e^{i k r}}{r}\left[B_{x}\left(\frac{k}{r} \underline{R}\right) \cos \phi+B_{y}\left(\frac{k}{r} \underline{R}\right) \sin \phi\right] \\
& E_{\phi}(\underline{r}) \sim-\frac{i k}{2 \pi} \frac{e^{i k r}}{r}\left[-B_{x}\left(\frac{k}{r} \underline{R}\right) \sin \phi+B_{y}\left(\frac{k}{r} \underline{R}\right) \cos \phi\right] \cos \theta
\end{aligned}
$$

In place of the theta-phi component description of the far field, the alternative elevation and azimuth component description is frequently chosen (cf. figure 1). These far-field components are given by

$$
\begin{aligned}
& E_{E}(\underline{r}) \sim \frac{-i k}{2 \pi} \frac{e^{i k r}}{r} B_{y}\left(\frac{k}{r} \underline{R}\right) \cos A \\
& E_{A}(\underline{r}) \sim \frac{-i k}{2 \pi} \frac{e^{i k r}}{r}\left[B_{x}\left(\frac{k}{r} \underline{R}\right) \cos E+B_{y}\left(\frac{k}{r} \underline{R}\right) \sin E \sin A\right]
\end{aligned}
$$

The radial component of the far field, which is perpendicular to each of the components in equations (4) and (5), is equal to zero.

The elevation (E) and azimuth (A) angles, shown in figure 1, are obtained from

$$
\sin E=\sin \theta \sin \phi, \quad \tan A=\tan \theta \cos \phi,
$$

whereas the usual spherical-coordinate angles theta $(\theta)$ and phi $(\phi)$ may be expressed in terms of the far-field spatial-frequency components $k_{x}$ and $k_{y}$ using

$$
\operatorname{Tan} \phi=\frac{k_{y}}{k_{x}}, \quad \sin \theta=\frac{\sqrt{k_{x}^{2}+k_{y}^{2}}}{k} .
$$

The alternative azimuth (a) and elevation (e) angles, depicted in figure 2 , are obtained from the expressions

$$
\sin a=\sin \theta \cos \phi=\cos E \sin A
$$


and

$$
\operatorname{Tan} e=\operatorname{Tan} \theta \operatorname{Sin} \phi=\operatorname{Tan} E \operatorname{Sec} A .
$$

We can express the magnitude of the far-zone electric-field vector, $|\underline{E}|^{2}=\underline{E} \underline{E}^{*}$, where * implies the complex conjugate, as

$$
|\underline{E}|^{2}=\left|E_{\theta}\right|^{2}+\left|E_{\phi}\right|^{2}=\left|E_{E}\right|^{2}+\left|E_{A}\right|^{2}
$$

Substituting from either (4) or (5) into the above expression results in

$$
|\underline{E}|^{2} \sim \frac{k^{2}}{4 \pi^{2} r^{2}}\left\{\left|B_{x}\right|^{2} \cos ^{2} E+\left|B_{y}\right|^{2} \cos ^{2} a+\left(B_{x} B_{y}^{*}+B_{x}^{*} B_{y}\right) \sin E \sin a\right\},
$$

where the argument, $\frac{k}{r} \underline{R}$, of $B_{x}\left(\frac{k}{r} \underline{R}\right)$ and $B_{y}\left(\frac{k}{r} \underline{R}\right)$ is understood.

Finally, we give some explicit relations between the vector-components which hold on the principal-plane cuts. Thus, for the principal plane $\phi=0$ we have:

$$
\begin{aligned}
& E=e=0, \quad A=a=\theta \\
& \underline{R}=r \sin \theta \underline{a}_{-x}
\end{aligned}
$$

and

$$
\begin{gathered}
E_{A}(\underline{r})=E_{\theta}(\underline{r}) \sim-\frac{i k}{2 \pi} \frac{e^{i k r}}{r} B_{x}\left(\frac{k}{r} \underline{R}\right) \\
E_{E}(\underline{r})=E_{\phi}(\underline{r}) \sim-\frac{i k}{2 \pi} \frac{e^{i k r}}{r} B_{y}\left(\frac{k}{r} \underline{R}\right) \cos \theta .
\end{gathered}
$$

On the principal plane $\phi=\frac{\pi}{2}$ the relationships become:

$$
\begin{aligned}
& A=a=0, \quad E=e=\theta \\
& \underline{R}=r \sin \theta \underline{a}_{y}
\end{aligned}
$$

and

$$
E_{A}(\underline{r})=-E_{\phi}(\underline{r}) \sim-\frac{i k}{2 \pi} \frac{e^{i k r}}{r} B_{x}\left(\frac{k}{r} \underline{R}\right) \cos \theta
$$




$$
E_{E}(\underline{r})=E_{\theta}(\underline{r}) \sim-\frac{i k}{2 \pi} \frac{e^{i k r}}{r} B_{y}\left(\frac{k}{r} \underline{R}\right) .
$$

It may be noted that a jump change in sign of the $\theta$ and $\phi$ components, due to the jump change in $\phi$ by $\pi$ radians upon passing through the coordinate-system origin, has been suppressed in writing expressions (10) and (11).

\section{A.2 Finite Fourier Transform Representation of the Plane-Wave Spectrum Integral}

We next require computational expressions for evaluating the apertureplane integral defined by (2). If we presume that $\underline{B}\left(\frac{k}{r} \underline{R}\right)$ is a bandlimited function of the spatial-frequency components $k_{x}$ and $k_{y}$, having bandlimits $-k_{x} \leq k_{x} \leq k_{x}$ and $-k_{y} \leq k_{y} \leq k_{y}$, then the aperture-plane integral (2) can be expressed as [2]

$$
\underline{B}\left(\frac{k}{r} \underline{R}\right)=\delta_{x} \delta y \sum_{m=-\infty}^{\infty} \sum_{n=-\infty}^{\infty} E_{t}\left(\underline{P}_{-m n}\right) e^{-i \frac{k}{r} \underline{R} \cdot P_{m n}} ;\left|k_{x}\right| \leq k_{x},\left|k_{y}\right| \leq k_{y} \cdot
$$

Here, $P_{-m n}=m \delta_{x-x}{ }^{a}+n \delta_{y-y}$, where $\delta_{x}=\frac{\pi}{K_{x}}$, and $\delta_{y}=\frac{\pi}{K_{y}}$.

Furthermore, if the aperture-plane tangential electric-field vector is restricted to a rectangular aperture of dimensions $a=N X \delta_{x}$ and $b=N Y \delta_{y}$, then the aperture electric field will be non-trivial only over the range $\frac{1-N X}{2} \leq m \leq \frac{N X-1}{2}, \frac{1-N Y}{2} \leq n \leq \frac{N Y-1}{2}$, so that the doubly infinite series in (12) may be replaced by two finite sums. Moreover, we can sample the transverse plane-wave spectrum vector $\underline{B}\left(\frac{k}{r} \underline{R}\right)$ at the equaliy spaced points $k_{x}=j \frac{k}{r} \Delta_{x}$ and $k_{y}=\ell \frac{k}{r} \Delta_{y}$, where $\frac{k}{r} \Delta_{x}$ and $\frac{k}{r} \Delta_{y}$ are the spatialfrequency sampling intervals, and where $j$ and $\ell$ are integers. The total number of $x$-coordinate spatial-frequency sampling points is $N_{x}$, and the total number of $y$-coordinate spatial-frequency sampling points is $N_{y}$, where $N_{x}>N X$ and $N_{y}>N Y$. The range on the integers $j$ and $\ell$ is

$$
-\frac{N_{x}}{2} \leq j \leq \frac{N_{x}}{2}-1 \text { and }-\frac{N_{y}}{2} \leq \ell \leq \frac{N_{y}}{2}-1 \text {. }
$$

so that the bandlimits are 


$$
K_{x}=\frac{k}{2 r} \Delta_{x} N_{x} \quad \text { and } \quad K_{y}=\frac{k}{2 r} \Delta_{y} N_{y} \text {. }
$$

The numbers $N_{x}$ and $N_{y}$ respectively correspond to the quantities NNX and NNY described in the computer-program documentation. For the sake of computer program compatability with existing software, the number of input data points should equal the number of output data points. This may be accomplished by zero-filling the input data array corresponding to data points outside the rectangular-aperture boundaries.

Although (12) is an exact expression if the aperture-field integration results in a bandlimited function, our restriction of the input data to a rectangular aperture is not compatable with this condition. Consequently, there will result an aliasing error with the finite-Fourier-transform relation, so that the actual finite-Fourier-transform relation becomes

$$
\begin{aligned}
& \underline{B}_{j \ell} \equiv \sum_{p=-\infty}^{\infty} \sum_{q=-\infty}^{\infty} \underline{B}\left(\frac{k}{r} \underline{R}_{j}+p N_{x}, \ell+q N_{y}\right)
\end{aligned}
$$

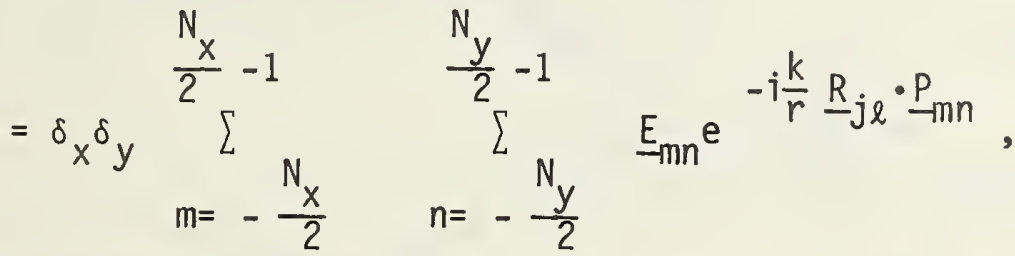

where the range on the integers $j, \ell$ is given by (13), and where we have written $\underline{E}_{m n}$ for $\underline{E}_{t}\left(\underline{P}_{m n}\right)$. Also, $\underline{R}_{s, t}=s \Delta_{x} \underline{a}_{x}+t \Delta_{y}{ }^{a}-y$, where $s, t$ take on the values indicated in (15). From (15), we see that $\underline{B}\left(\frac{k}{r} \underline{R}_{j l}\right)$ is replicated as $\underline{B}\left(\frac{k}{r} \underline{R}_{j+p N_{x}, l+q N_{y}}\right)$ for $p, q=0, \pm 1, \pm 2$, etc.; thus $\underline{B}_{j \ell}$ is formed, within the range on $j$ and $l$ given in (13), by summing contributions from the primitive function $\underline{B}\left(\frac{k}{r} \underline{R}_{j \ell}\right)$ to those non-negligible contributions, from the overlapping ends of these replicated functions, that arise from spatial-frequency values outside the assumed bandlimits $K_{x}$ and $K_{y}$. Here, of course, $K_{x}$ and $K_{y}$ simply correspond to the quantities $\pi / \delta_{x}$ and $\pi / \delta_{y}$, rather than to actual bandlimits. It should be noted that an analytical transition from the right-hand side of (12) to the right-hand side of (15) also involves a replication of $\underline{E}_{t}\left(\underline{P}_{m n}\right)$, so that both the input and output functions in the finite Fourier transform relation (15) are doubly periodic with periods $N_{x}$ and $N_{y}$. However, there is no overlap of the replicated input functions within the integration interval. 
Although the finite-Fourier-transform relation (15) does not give a perfect evaluation of the aperture integral (2), it can be recognized that aperture-plane integration of a physical electric field will produce a virtually bandlimited function. This implies that the approximation

$$
\underline{B}\left(\frac{k}{r} \underline{R}_{j \ell}\right) \simeq \underline{B}_{j \ell} ; \frac{-N_{x}}{2}<j<\frac{N_{x}}{2} \quad, \frac{-N_{y}}{2}<\ell<\frac{N_{y}}{2}
$$

will be valid provided $k_{x}$ and $k_{y}$ are large enough. This in turn implies that $\delta_{x}$ and $\delta_{y}$ must be sufficiently small.

One difficulty that arises with utilizing (15) is that fast Fourier transform (FFT) subroutines require non-negative integer values for the indices $j, l, m$, and $n$. Fortunately, this difficuity is readily resolved using the periodic character of $\underline{B}_{j l}$ and $\underline{E}_{m n}$. Thus we have

$$
\begin{aligned}
& \frac{1}{\delta_{x} \delta_{y}-j l}=\sum_{m=-\frac{x}{2}}^{\frac{N_{x}}{2}-1} \sum_{n=-\frac{N_{y}}{2}}^{\frac{N_{y}}{2}-1} \sum_{-m n} e^{-i 2 \pi\left(j m / N_{x}+\ell n / N_{y}\right)} \\
& =\sum_{m=0}^{N_{x}-1} \sum_{n=0}^{N_{y}-1} \underline{E}_{m-\frac{N_{x}}{2}, n-\frac{N_{y}}{2}} e^{i \pi(j+l)} e^{-i 2 \pi\left(j m / N_{x}+l n / N_{y}\right)} .
\end{aligned}
$$

Finally, we obtain

$$
\frac{1}{\delta_{x} \delta_{y}} \underline{B}_{j+\frac{N_{x}}{2}, \ell+\frac{N_{y}}{2}}=e^{i \pi(j+\ell)} \sum_{m=0}^{N_{x}-1} \sum_{n=0}^{N_{y}-1} e^{-i \pi(m+\ell)} \underline{E}{ }_{m-\frac{N_{x}}{2}, n-\frac{N_{y}}{2}} e^{-i 2 \pi\left(j m / N_{x}+\ell n / N_{y}\right)} .
$$

This result enables us to integrate over the aperture surface, $-T_{x} \leq x^{0} \leq T_{x} ;-T_{y} \leq y^{0} \leq T_{y}$, where $T_{x}=\frac{1}{2} N_{x} \delta_{x}$ and $T_{y}=\frac{1}{2} N_{y} \delta_{y}$, using standard FFT-program format. The output of the FFT routine is a function of $j$ and $\ell$, which range over the values 


$$
0 \leq j \leq N_{x}-1, \quad 0 \leq \ell \leq N_{y}-1
$$

Consequently, since $\underline{B}_{j, l}$ is periodic in $j$ and $\ell$ with periods $N_{x}$ and $N_{y}$, respectively, by using (17) the FFT output can be plotted directly as though the range on $j$ and $\ell$ were as given in (16).

Finally, we write down expressions that are compatible with the problem of computing the far field on the plane cuts. Thus, for the plane $k_{y}=$ const. we have

$$
\ell+\frac{1}{2} N_{y}=\frac{N_{y}}{S_{y}} \sin E,
$$

where $S_{y}=\frac{\lambda}{\delta_{y}}$ and $E$ assumes a fixed value. We can now collapse the summation over $y$ (i.e.., reformulate the problem so as to just carry out an FFT on data formed by summing the input-matrix columns) to obtain

$$
\begin{gathered}
\frac{1}{\delta \delta^{\delta} y} \underline{B}+\frac{N_{x}}{2}, \ell+\frac{N_{y}}{2}=e^{i \pi j} \sum_{m=0}^{N_{x}-1} e^{-i \pi m} \sum_{n=0}^{N_{y}-1} \\
\left.\quad{ }_{m-\frac{E}{2}, n-\frac{N_{y}}{2}} e^{-i\left(\frac{2 \pi}{S_{y}} \operatorname{Sin} E\right)\left(n-\frac{N_{y}}{2}\right)}\right\} e^{-i 2 \pi j m / N_{x}} .
\end{gathered}
$$

Similarly, for the plane $k_{x}=$ const. we have

$$
j+\frac{1}{2} N_{x}=\frac{N_{x}}{S_{x}} \sin a,
$$

where $S_{x}=\frac{\lambda}{\delta_{x}}$ and a assumes a fixed value. We now collapse the summation over $x$ (i.e., reformulate the problem so as to just carry out an FFT on data formed by summing the input-matrix rows) to obtain

$$
\begin{gathered}
\frac{1}{\delta \delta^{\delta} y} \underline{B}{ }_{j+\frac{N_{x}}{2}, \ell+\frac{N_{y}}{2}}=e^{i \pi \ell} \sum_{n=0}^{N_{y}-1} e^{-i \pi n} \sum_{m=0}^{N_{x}-1} \\
\left.\qquad \underline{E}{ }_{m-\frac{N_{x}}{2}, n-\frac{N_{y}}{2}} e^{-i\left(\frac{2 \pi}{S_{x}} \sin a\right)\left(m-\frac{N_{x}}{2}\right)}\right\} e^{-i 2 \pi \ell n / N_{y}} .
\end{gathered}
$$




\section{REFERENCES}

[1] Collin, R. E., Zucker, F. J., Antenna Theory Part I, McGraw Hill (1969).

[2] (a) Kerns, D. M. Correction of near-field antenna measurements made with an arbitrary but known measuring antenna, Electronics Letters 6, pp. 346-347 (1970).

(b) Kerns, D. M. Plane wave scattering matrix theory of antennas and antenna-antenna interactions, NBSIR 78-890 (June 1978) (forthcoming as NBS Monograph 162).

[3] Yaghjian, A. D. Upper-bound errors in far-field parameters determined from planar near-field measurement, Part I: Analysis, NBS Tech Note 667 (0ct. 1975).

[4] Landau, H. J. Sampling, data transmission, and the nyquist rate, Proc. IEEE 55. \#10, 1701-1706 (0ct. 1967).

[5] Newe11, A. C. Planar near-field measurement techniques, (lecture notes for the NBS short course, Antenna Parameter Measurement by Near-Field Techniques, 7-11 Juiy 1975).

[6] Cooley, J. W., Lewis, P. A. W., Welch, P. D. The fast Fourier transform algorithm and its applications, IBM Research Paper RC-1743, (Feb. 9, 1967).

[7] Johnson, C.C., Field and Wave Electrodynamics, McGraw Hi11, 1965. 


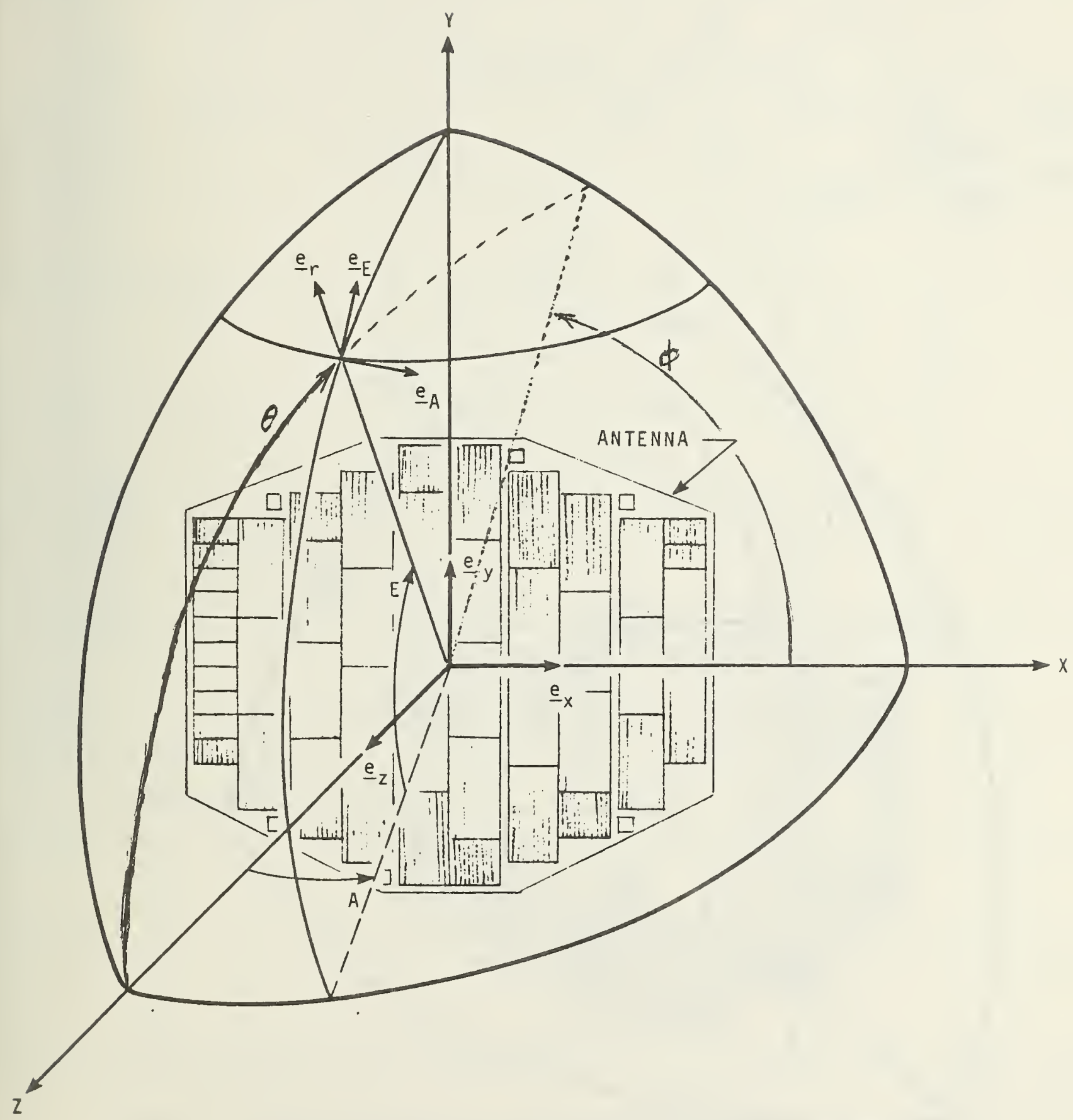

Figure 1. Antenna coordinate system using $A$ and $E$ spherical angles with $y$ as the polar axis. 


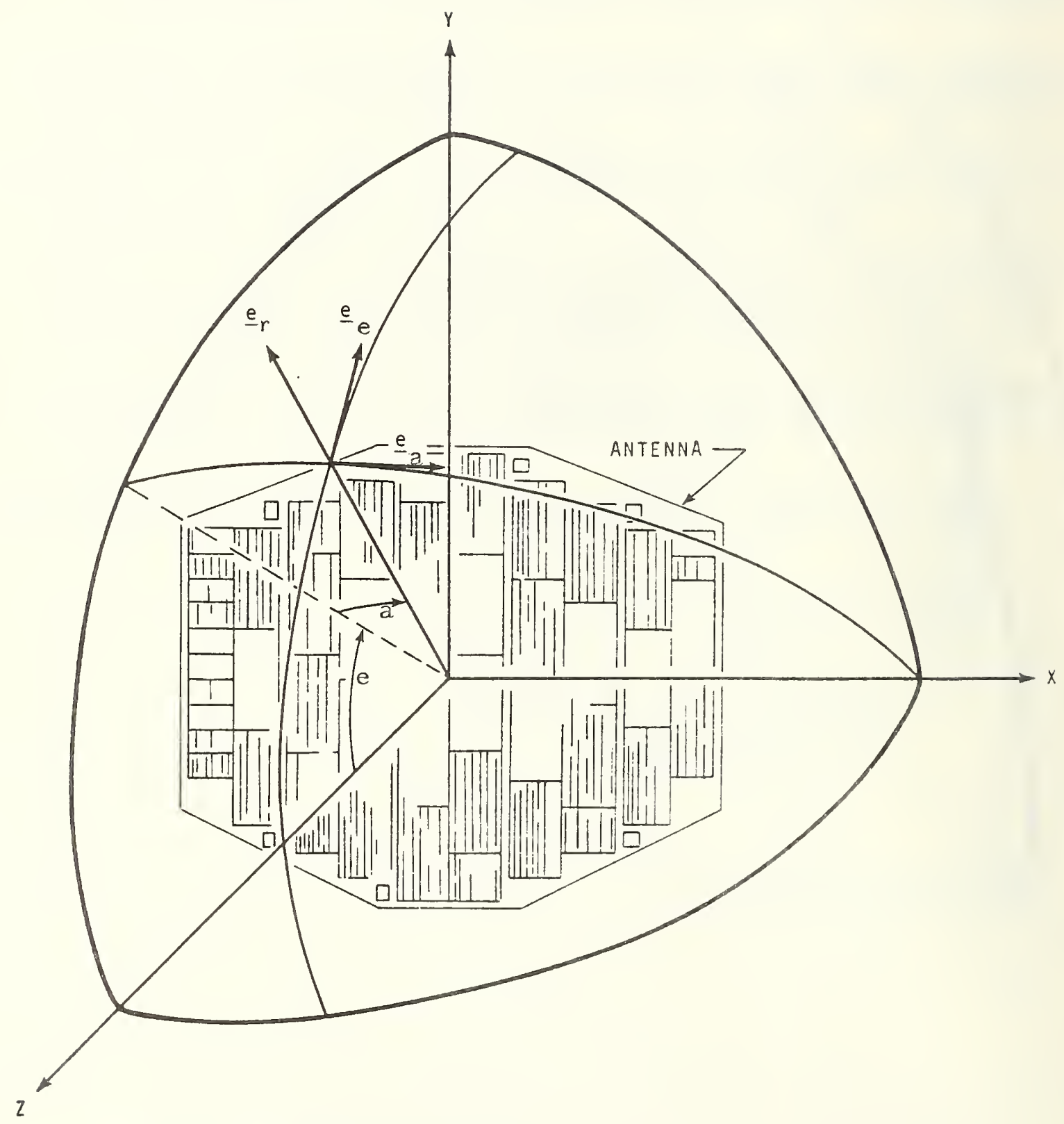

Figure 2. Antenna coordinate system using a and e spherical angles with $x$ as the polar axis. 


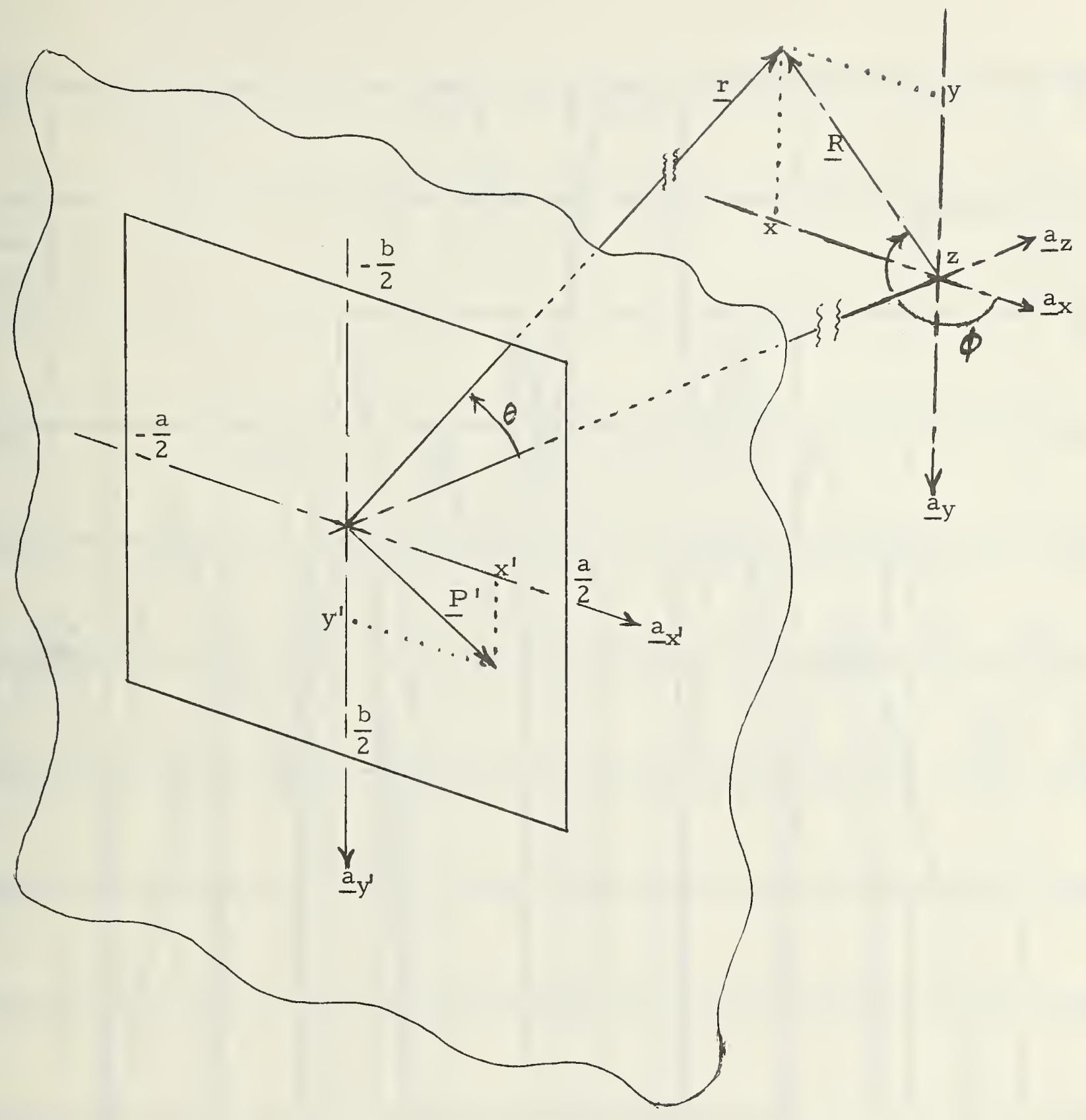

Figure 3. Problem geometry, showing the rectangular aperture within an aperture plane and the far-zone position coordinates. 


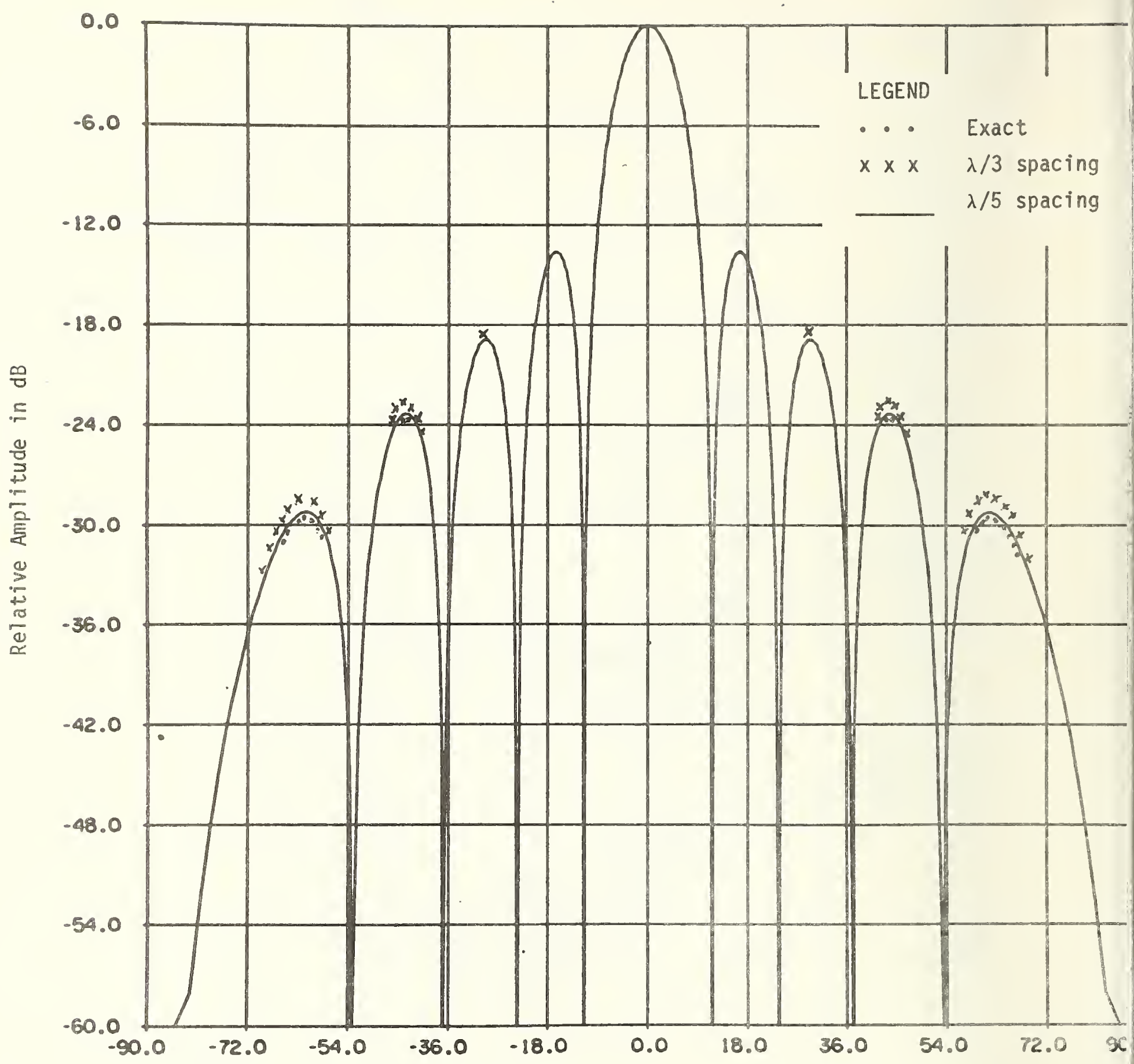

Theta in degrees

Figure 4. The principal plane cut $\phi=\frac{\pi}{2}$. PHI-component amplitude plot for a 5-wavelength-wide slit aperture (varied data-point-spacing increments). 


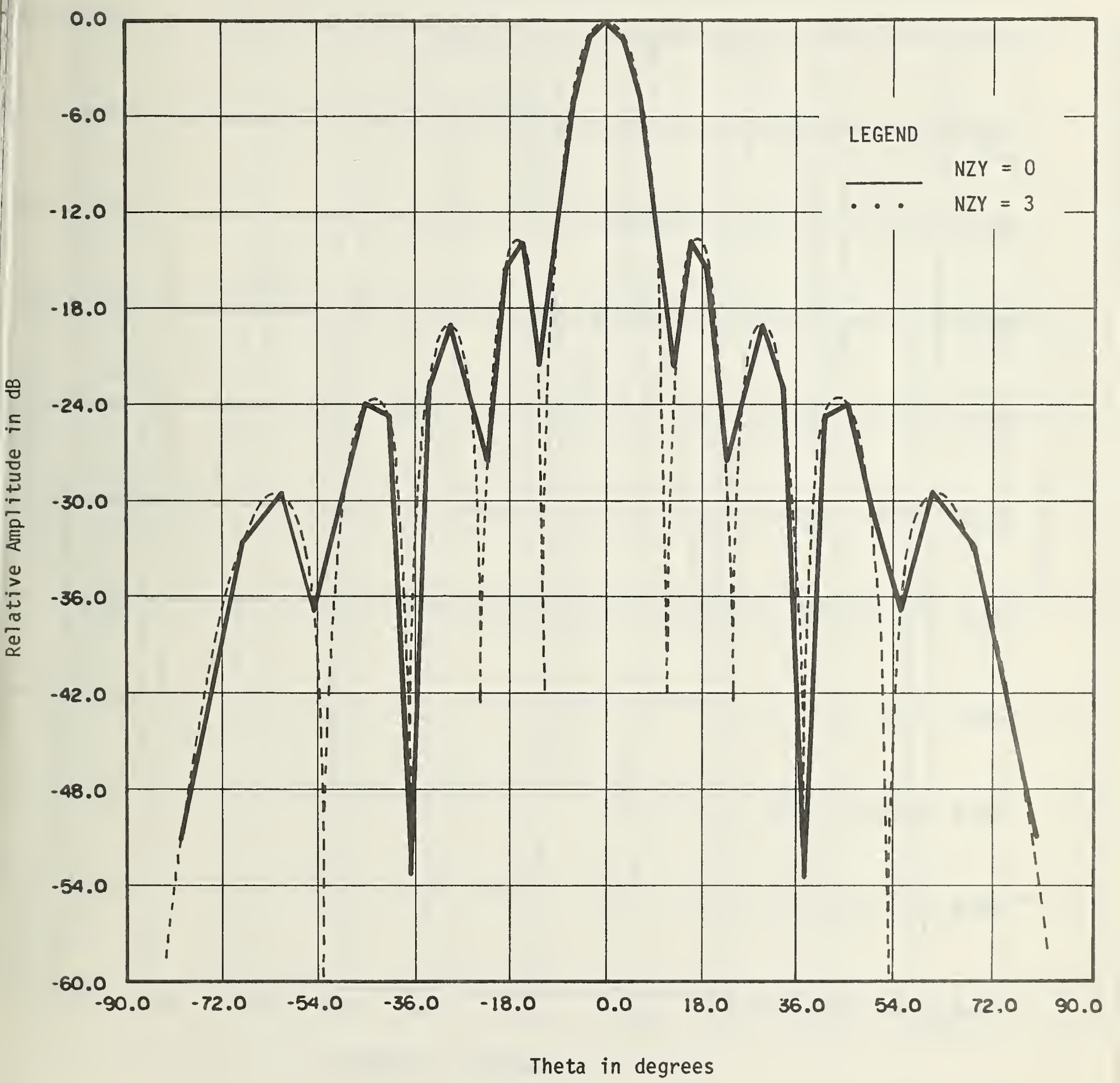

Figure 5. The principal plane cut $\phi=\frac{\pi}{2}$. PHI-component amplitude plot for a 5-wavelength-wide slit aperture

(varied Fourier integration ranges). 


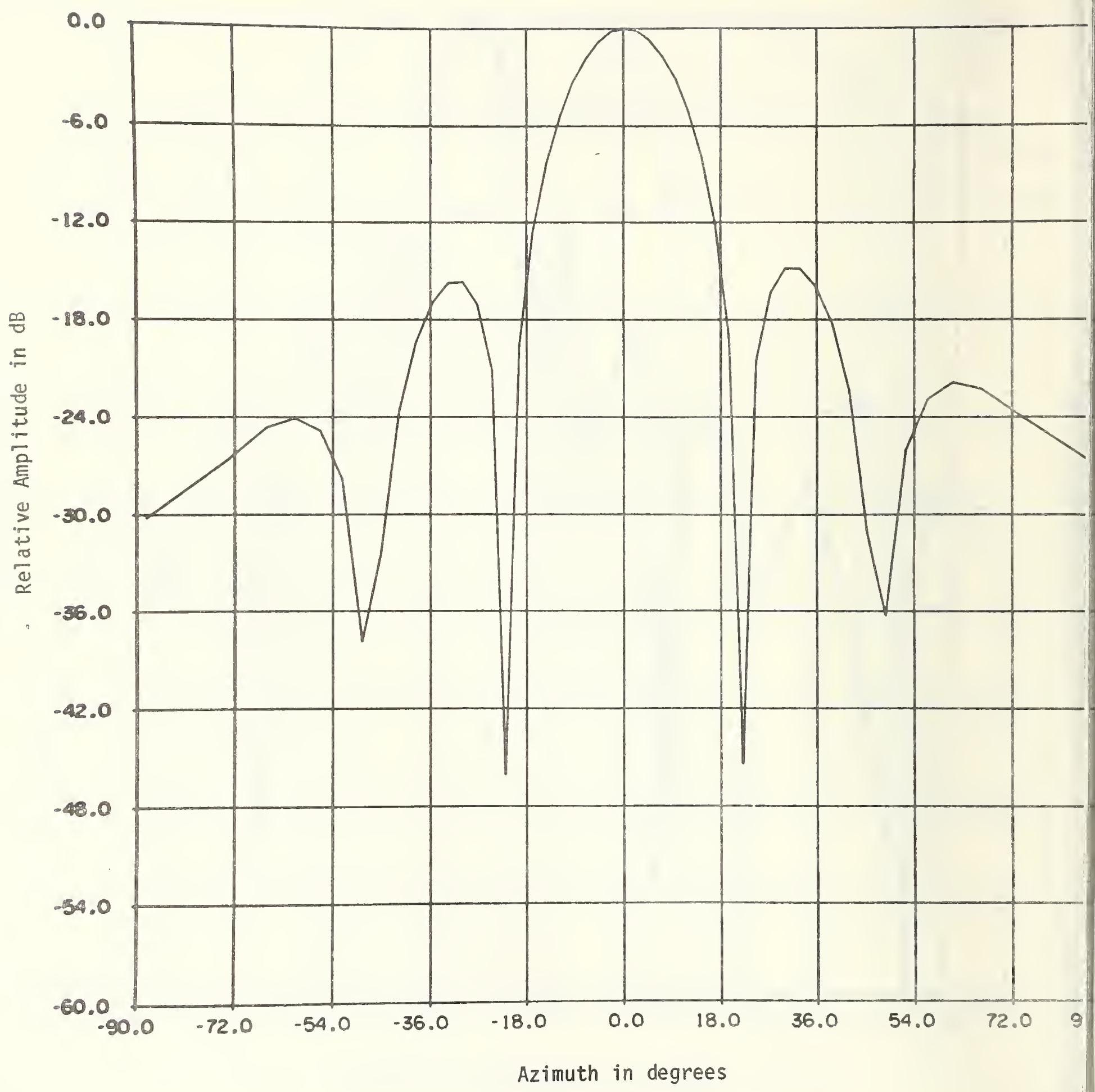

Figure 6. Antenna pattern magnitude for a uniformiy excited circular
aperture. Y-plane cut with constant elevation angle $\mathrm{E}=10^{\circ}$. 


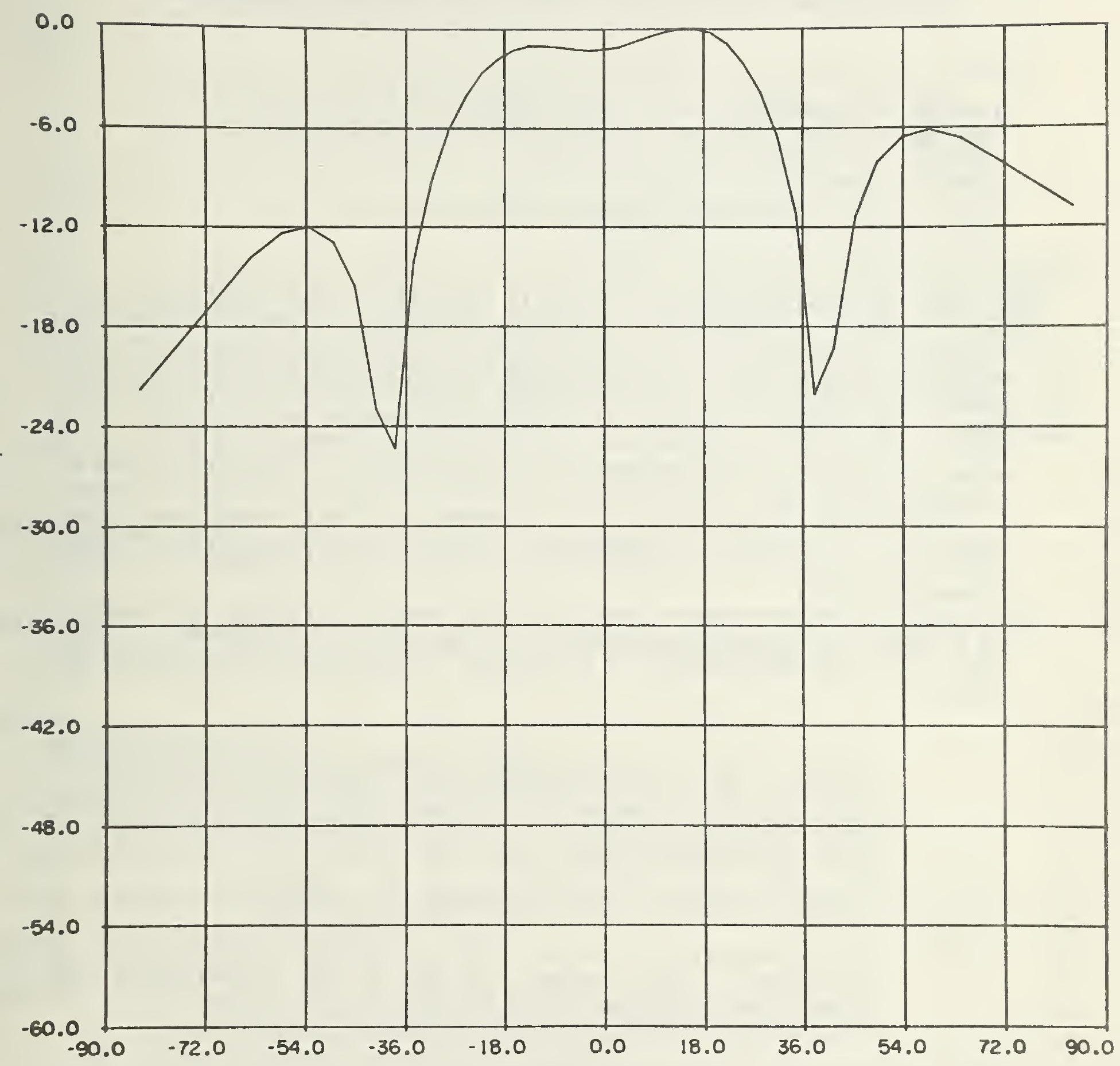

\section{Azimuth in degrees}

Figure 7. Antenna pattern magnitude for a uniformly excited circular aperture. Y-plane cut with constant elevation angle $\mathrm{E}=30^{\circ}$. 
Computer Program Listing for Computing Azimuth and Elevation Vector Components Along User-Specified X- and Y-Plane Cuts in the Far Field Arising from a Prescribed Rectangular-Aperture Field Distribution

PROGRAM FAREA (INPUT, OUTPUT, TADEI=INPUT)

DIMENSION STOF $(1024)$, EXPX(102L), EXPY (1024), EI (4096)

DIMENSION THETA 1 I 24$)$, DATA $23: 3\}$

COMPLEX STOR,EXPX,EXFY, EI, ZZ

EQUIVALENCE (THETA,STOP), (EXPX, OATA)

CATA (NMAX $=4$ D24), (N)TMEN $=4095$ )

94 FORMAT $4 F 7.1 \times 2 I 3,2 F 5 \cdot 3,5 \times A 1:)$

95 FORMAT $11 H 1,2 X \equiv 2 H A L P H A=X-C O O E N$ NATE APERPURE DTMENSION IN WAVELENG OHS, $9 X$ 1HBETA $=Y$-COORJTNATE APEP IURE DIMENSION IN WAVELENGTHS/3X $37 H S$ $P X=R A T I O$ OF WAVELENG?H TO $X=$ COOROINATE DATA-POINT SPACING, $4 X 57 H 5 Y=R$ DATIO JF WAVELENGTH TO $Y=C O O R D I N A T E$ DATA-POTNT SPACING/3X 4 SHNZX $=X-C$ ROCRDINATE ZERO-FILL-REGIOA COIIRLING FACTOR, $12 \times 49 H N 7 Y=Y-C O O R D I N A T E$ SZERO-FILL-REGION DOJBLING FAE OD/3XELHA=AZ:MJTH ANGLE IAT ZEPO JEG TREES ELEVATION OF $\triangle 7$ IMUTH-PLANE CUT, $14 \times 4 Q H E=E L E V A T I D N$ ANGLE O= EL UEVATION-PLANE CUT/3X39HBANNER=18-CHARACTER PLOT IDENTIFICATION, $4 X$ V4 5 HNNX, NNY =NUMBEE OF TERMS IN $X$ OR IN Y FF: SUM, $6 \times 25 H N N X=2 * * M 4 X$ W, NNY $=2 *$ MMY/// BH ALPHA $=, F A, 3,4 X E H B E T A=, F 9,3,4 X 4 H S X \equiv, F 7.3,4 X$ $X 4 H S Y=, F P, 3,4 \times 5 H N Z X=, I 3,4 \times 5 H \backslash Z Y=, I 3,4 \times 3 H A=, F 5.1,4 X 3 H E=, F 5.1,4 X$ YPHBANNER, A 10, $1 \mathrm{H}, / / 24 \times 5 \mathrm{HNNX}=, 15,10 \times 5 \mathrm{HMMX}=, I 3,32 \times 5$ HNNY $=, I 5,10 \mathrm{X}$ ZTHMMY $=, I 3 / / / 1$

96 FCRMA: (1H, 25X7LHAFFAY DIMENSTONS TOO SHALL OR ILLEGAL OR ELSE E O IR A EQUALS 90 DEGREES/11X5HNVX $=, 15,5 \times 5 \mathrm{HMMX}=, 14,10 \times 5 \mathrm{HNNY}=, 15,5 \times 5$ $2 H: M Y=, I 4,13 \times 23 H C O Y P U T=0$ EI JIMENSION $=, I 6,1: X^{2} \mathrm{HE}=, F 5.1,5 \times 3 H A=$, $3 F 5.11$

COMPUTATION OF THE FA? FIELO ALONG SPECIFIED PERPENDICULAR AZIMUTH- ANO ELEVATIOH-PLANE CUTS, WHERE THE FAR-FIELD EXCITATION SORRESPONJS TO A GIVEN NEAR-FTELD UISTRIBUTTON IN A SPECIFIED APERTUEE. IN ADOITION, THE FAR-FIELD ANTENNA PATPERN ALONG THESE SPEOTFIED CUTS IS ALSO SOMOUTEO.

THE DATA SPACING BETWEEN $X$ - OR Y-COOROINATE ELEMENTS IS ASSUMEO TO BE FIX MHAX =DIMEMSION OF AFRAYS STOF AND HETA. DIMENSION OE ARRAY DATA SHOULD ERUAL 2*NHAX. NCIMEN IS THE DIMENSION OF ARRAY EI. NOIMEN SHOU - EQUAL TWTOE THE SUM O - HE X ANO YOEFT IIMENSTOVS THE MAXIMUM USEFUL VALUE OF NOIMEN IS L NMAX.

INPUT PARAMETEPS.

ALPHA=APEFTURE WIOTH IN WAVELENGTHS (X-COOROINATE) AETA=APEFTURE LENGTH IN WAVELENGTHS PY-COOROTNATES $5 X=R A T I O$ OF WAVELENGTH TO $X$-COJPDINATE DATA-OJINT SPRSI SY =OATIO OF WAVELENGTH TO Y-COSRDINATE JATA-POINT SPACI NZX = NUMBER IF EXTPA DOUBLINGS OF THE ZERO-FIL- REGION FOR THE X-FAR-FIELD-COOROINATE FFT. (NORMALLY=1) NZY = NUMBER OF EXTRA DOUBLINGS OF THE ZERO-FI'- REGION FOR THE YOFAR-FIELD-JOOR J INATE FFT. (VOJMALLY=1) $A=A$ T.IMUTH ANGLE (AT ZERO DEGREES ELEVATION), IN CEGKEES, OF A?IMUTH-PLANE CUT. EE ILEVATION ANGLE, IN CEGPEES, CF ELEVATION-DLANE CUT, EANNER = $\$ B-$ BHARACTER GRADY I DENTIFICATION 
THE INPUT DATA IS ASSUMED TO EE SUEDLTEO AS ROWS OF X-TOCRNINATE DATA, EACH FOW CCREESPDNOTNG TO A FIXEN VALUE OF THE Y-COORDINAALL OF THE E-SUB-X CA- $\triangle$ IS TO BE SUPDLIE? FIRST, AND THEN THIS INPUT DATA IS TO BE FOLLOWED PY ALL OE THE E-SUB-Y JATA. THE PFOGFIM OBTAINS THE INPUT OATA THDOUGH REPEATEO CALLS TO THE USEF-JUPDLIEE SUBPRUTINE GE- $\triangle P A Y$.

EACH CALL TO SUPRCLTINE GFTARAY RFSULTS IN A ROW OF NX TOMPLEX DATA POINTS, = ACH SUCCESSIVE CALL COPRFSPONOING TO A RON SUCCESSIVELY FURTHEF BELOW THE TOP OF THE ADEPTUFE. HE-E, NX IS ENUAL TO THE FFOOUS SX * ALPHA. THE NUMBSP OF ROWS. OD THE NUMBER OF CALLS TO GETARAY, IS GIVEN QY NY = SY * B=TA.

NUMREO OF DATA CAFOS $1 / 5 E D$ BY PROGPAM CUPROUTINES $=3$.

FOLLOWING THE COMPLETECN DF A GIVEN TAP-FIFLO COMPUTATYON $\triangle L O V G$ SPERIFIED PEDPENCICULAO ATIMUTH ANO ELEVATION PLANES, HE PROGR:M PETURNS TO THE BEGINING TO READ \& NEW DATA CAEN ANT START $\triangle L L$ DVED AGAIN ON A NEW FAO-FIELD COMPUTATION. THIS TIME, HOWEVED, THE PLOTTING FOUTINE PARANETECS ANE LEGEND THAT WERE F =AD IN, ON THE FIPST TIME THFOUGH THAT SUBOCUTINF, ADE SIMPLY RECALLEO AMD USE? RVER LGAIN. THE USER MUST MAKE SURE SURE OUTINE G TTADCY CAN SUPPLY A NEW SET OF $N=A F-F T E L D$ DATA IIONN EEESTARTING TH DEOGEAY.

PAPAMETEP DEAO IM

1 READ $94, \triangle L P H A, B E T 3, S X, C Y, N Z X, Y T Y, \triangle, E, P A N N E$

IF (EOF (1).NE. - G G TO $? 5$

CALCULATION OF NX AND MY

$N X=0 . E * 5 X * A L P H A$ \& $N X=2 * N X+1$ \& NYY=C. $* S Y * D E T \Delta$ \& NY=?*NY+1

$S X=N X / A L P H A \& S Y=P Y Y / B E T A$

CALCULATIOM OF NNX ANR HNY, ALCNE, WITH MMX AN MMY $M M X=M M Y=N N X=N N Y=1$

$2 M M X=M M X+1$ \& $N M X=2 * N N X$ \& IF $(N N X . G T, N X)$ 3,?

$3 N N X=2 * N N X$ IF $(N Z X)+4, \varepsilon, 4$

$44 N N X=N N X / 2 \& M M X=M: 4 X-1$ \& $G 0$ TO 5

4 Er $5 M=1, N Z X$ * $M M X=\operatorname{M} M X+1$

$5 N N X=2 * V ! N X$

$6 M * Y=M: Y+1$ \& NN:Y=2*NNY IF (NNY, GT,NY) 7,6

7 NPY $=2^{*} N N Y$ \& IF $(N Z Y)-5,18,9$

45 NNY $=$ NNY/2 \& MMYMNY $=1$ \& 60 - $\cap 1 ?$

$8 D O Q \quad M= \pm$, NZY \& $M M Y=M M Y+1$

9 NNY $=2$ *NNY

$10 \quad M M=M A X=(M M X, M M Y) \quad N N=M A X S(N N X, N N Y) \quad N 7=N H X+N N Y$ \& $\quad I=? * N D$

IF $\left(J, G^{\top}, N D I M E N, C P, N N, G T, N M A X, 7=, M M, G^{-}, 14\right): 1,12$

11 PEINT 96, NNX,MMX, MNY, MMY,J,E, A C CALL EXIT

C INPUT PAFAMETED FRINIT-OUT

12 DEINT 3E, ALOHA, BETA, SX, SY,NZX, NZY, A, E, B2NNER, MNX, MMX, NNY, YMY

COMFUTATTON CF AFEFTURE-DA'A FOSTTTOA WITHEN "H- IN EGRATION INTE=VAL

FLCTOR=1.:/ $(S Y * S Y)$ \& IOX $=(N N X-N X+1) / 2 \& I J Y=(N N Y-N Y+1) / 2+N N X$ SINE=SIN(E. $1745329251734 ? * 2)$ क SINA =SIN(0.017452292519943*4)

COMPUTATION OF AFEOTUEF DATA-FCIN SDACINGS

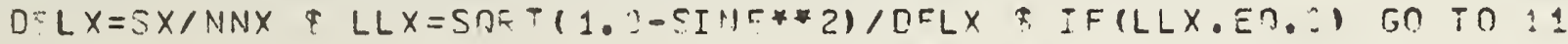

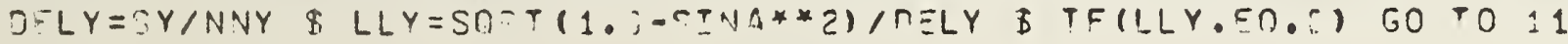


C RE-ZEROING OF INTEGRAL FIELC

DC $13 M=1, J$

$13 E I(M)=(0,0,1$

C COMPLTATION OF CONSTANT EXFONENTIAL MULTIDLICATION EACTOF - YAPLAYE CUT $Z Z=C E X P(C M P L X(0 ., 6.2931853071>96 * S I N E / S Y))$

$J=(N Y-1) / 2 \& K=J+1 \&$ EXPY $(K)=(1, ., 3$.

$D O 14 \quad M=1, J \& L=K-M$ \& $L L=K+M$

$\operatorname{EXPY}(L)=Z Z * \operatorname{EXPY}(L+1)$

$14 \operatorname{EXPY}(L L)=\operatorname{CONJG}(E X P Y(L))$

C COMPUTATION OF CONSTANT EXPONENTIAL MULTIPLICATION FACTOF - XODLUE CUT $Z Z=C E X P(C M P L X(0 ., 6.2831853371 ; 95 * S I N A / S X))$

$J=(N X-1) / 2 \& K=J+1 \& E \times P X(K)=(1,0,3$.

$D O 15 M=1, J \quad \& \quad L=K-M$ क $L L=K+M$

$\operatorname{EXPX}(L)=Z Z * E \times P \times(L+1)$

$15 E \times P X(L L)=C O N J G(E X P X(L))$

C DO LOOP TO COMPUTE TWO PLANE-CUT INTEGRALS OVER APERTURE-FIELD VECTOP $D O 21 I=1,2$ \& $M X=N N^{*}(I-1)$ \& IX $=M X+I X$ \& IY $Y X+I$ ? $Y$

C SET-UP OF INTEGPAND - COLLAFSE DII X-ANO Y-PLAN= CUTS

$0016 K=1$, NY $J=K+I Y$

CALL GETARAY (STOF,NX)

DO $16 \quad L=1, N X$ \& $N=L+I X$

$E I(M)=E I(M)+E X P Y(K)+S T O=(L)$

$16 E I(J)=E I(J)+E X P X(L)+C T O R(L)$

C INITIALIZE X-COMPONENT PAPAMETERS FOF FFT INTEGOA-TON $N X Y=N X \& M M=M P X \& N N=N N X$ \& $J=?$

$17 I Z=I X+N X Y \quad \& I I=I X+1$ \& IF $(N D N(N X Y / 2,2) \cdot E 0.0) \quad I 1=I 1+1$

C PRE-FFT MULTIPLICATION $\cong Y(-1) * A M$

OD $18 M=I 1, I 2,2$

$18 E I(M)=-5 I(M)$

C FFT COMPUT ITION

CELL CCFFT2 (EI $(M X+1), M M,-F A C T O D,-1)$

$I 1=M X+2 \& I 2=M X+N M$

C POSY AFFT MULTIPLICATION BY $(-1) * \mathrm{~J}$

$0019 M=I 1, I 2,2$

$195 I(M)=-E I(M)$

If $(J .50 .0) \quad 20,21$

C INITIALIZE YOCOMPONENT PAPANETERS FOR FFT INTFCQATION

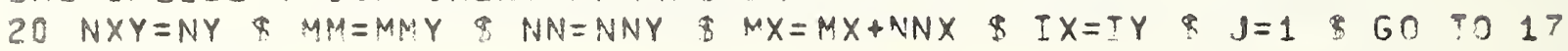

21 CONTINUE

C INITIALIZE Y-PLANE-CUT PARAMETERS FOR VECTOP-COMPONENT AND PATTERN COMP. $N N=N N X$ \& $L L=L L X \& D E L=D E L X \& \because X=J=3$ \& $\triangle N G L==$

$V=S I N \equiv \& V V=V * 2 \& C \cap D E=S C O+(1, ?-V V)$

C RESTEICT COMFUTATIONO TO DOLAP SOATIAL-FPERUEHCY ANGLES IN VTSIDL DANGE

$22 N X Y=N Y Y / 2+1$ क IF (NXY.LT.LL+2) ? ?,?L

$23 I:=M X+1$ \& IZ $=M X+N M$ \& $G 0$ TO 25

24 IL $=3 X Y-L L+M X * I 2=I 1+2 * L L$

$25 K=I 1-1$ \& $N X Y=N X Y+X X$ 
VEC CF-COMDONENT COMPUTA ION

$D O 33 \quad M=I 1, I 2 \quad \& \quad L=M-K$ \& $L L=M+I n$ \& $U=(M-M I X Y) \times D E L \quad$ Q SOST $=U * Z * V V$

IF $(J . E R .3) \quad 26,27$

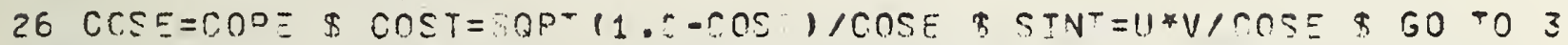

27 IF (U. $: 0.1 .0) \quad 28,2$ ?

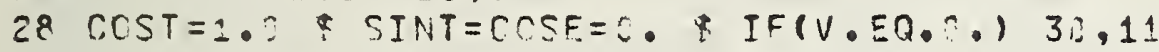

29 COSE $=S O F T(1 . C-U * 2)$ S COST $=S O=T(1.0-\operatorname{COST}) /$ SNC $=\$ S I N T=U * V / C D C E$

30 THETA $(L)=57.295779513082 * \Delta S I N(U / C O P F)$

$E I(M)=(0 ., 1.0) *(E I(M) * C O S E+E I(L L) * S I N T)$

$33 E I(L L)=C M P L X(\cdots, C O S T) * E I(L L)$ \& $L L=I 1+N O$

VECTCG-COMPONENI PLOTTING

CALL PAYPLOT (L, EI (I1), THETA, DATA, 2*NN,BANN=?, ?, CNGL

CALL PA:1DLOT (L, EI (LL), TFFTA, DATA, 2*NN, BANNFE, ?, ANGL =)

AN? ENNA -PATTERN COMPUTA T ON

DC $34 \quad I=I 1, I 2$ \& $L=M-K$ \& $L L=M+I C$

34 DETA $(L)=S \cap C T(F E A L(E I(M) * C C N J S(E T(M))+E I(L L) * C N N J G(E T(L L)))$

ANTENNA-PATTEFN PLOT'ING

CALL PAMPLOTIL, E. THETA, CATA,L, BANNEF, I, ANGLE)

IF (J.EQ. I) 35,1

INITIALITE X-PLANE-CUT =AFAME-ERT FOR VECTOS-COMPONENT AND PATTERM COMP.

$35 N A=N N Y \$ L L=L L Y \& O E L=? E L Y \& M X=N N X \& J=1$ \& $\& N G L 5=A$

$V=S I N A$ S $V V=V * * 2$ \& COPE=Sח $=-(1 . C-V V)$ \& $60-02 ?$

36 CONTTNUE

END

SUBROUTINE PAMPLOT(N. Z2, XVALU-, DATA, N2, GANNER, MODE, ANGLEI

OEMENSION ES(N), XVALUE(N), CATA (N?)

CCMPLEX ER

DIMENSION HEAD (9), YMAX(2), YMIN (2), AMP(4), CAM(?)

DIMENSION BP(L), ELAZ 2$), C$ CMP $F)$

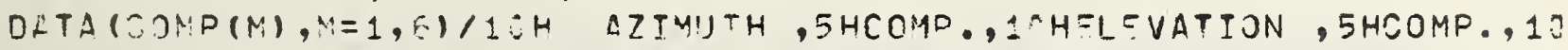

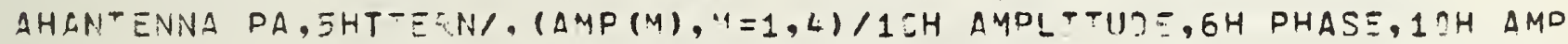

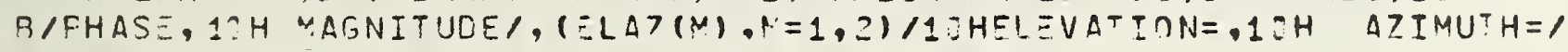

DATA(CAI! 1$)=1: H$ RELL CA), (CAM (2) =1CHCOMPLEX DA)

DFTA $(K=3),(I A=1),(I Q=1)$

99 FORMA- $(2 X I 1,3 F 7.1, I ?)$

160 FCFMA ${ }^{\top}(\angle H A M P=, G 8,2, A 12, F 3 . \cap, A: 3, A 5)$

$1 C 1$ FCRMAT $(-A 1 O)$

102 FOFMAT $\left(1 H^{*}, 10 \times 1 H^{*}, 9 A \pm \cap, 1 H^{*}\right)$

103 FOFMAT (1H1,15X2

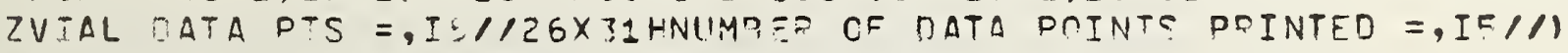

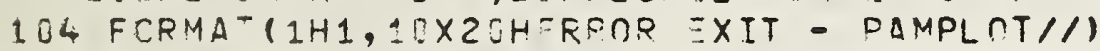

1 IS FCPMAT $\left(1 H 3,3 X 3 H N O=, I ?, ? \times 5 H X M I N=, F 7.3,3 X=H X^{\prime} \cdot 9 X=, F>.3,3 \times 8 H Y M I N(1)=\right.$ $1, F 7.3,3 X 8 H Y N A X(1)=, F ; \cdot 3,3 X R H Y M I N(2)=, F 7,2, \pi X R H Y M \Delta X(2)=, F 7.3,3 X, 14 H$ 2PEINT SPACING $=, I 3 / 11$

106 FCRMAT (1H://25XLLHALL INFUT 7ATA VALUFS TO DAMPLCT ARF TRIVIAL//)

107 FORMAT (E (F1U, . GI . 4,FT .3))

108 FCFMA- 1 HH, 25X24HMAX MIIM CA-A AMPLITUNE =,G1 $.6 / / 1$

109 FCRMAT (E:X, A1E, 15HTA PLCTTING NODE//)

11 C FCRMAT (3(FR,2, GG, Z)) 
ROUTIRE TO SET UP AFRAYS FOO PLOTPING AMPLITUOE ANO PHASE OF THE COMLEX AFFAY ER. TIMENSION OF APRAY ES EQUALS $N$. DATA PLOTTEO VERSUS ABSCISSA ARRAY XVALUE.

SOMPLEX IUPUT DATA ASSUMED IF MOCE=?. IF MODE=1, HOWEVEZ, IT IS ASSUMED THAT ONLY REAL-AMPLI UNE JATA IS TO BE PLOTTED. THIS FEAL-AMPLITUCE DA-A WILL BE ACSUMED TO $9 E$ IN ARFAY DATA. ARFAY DATA IS ALWAYS SHANGED BY THE PSOSRAM, WHILS AFRAY FP IS LEFT AS I' WAS ON ENTRY TO THE PROGPAM. IF MODE=1, ARPAY ER IS IGNORED.

ROUTINE ALSO DRINTS OUT THE AMPLITUSE, PHASE, ANM ABSCISSA VALUE AT A SELECTED NIJMEER OF DATA POINTS. USER SOECIFIES THE POINT SPACING BETWEEN THE DA A POINTS TO BE PRINTE? AND THEN BATA POINTS WTLL BE SELECTED FOF PRINTING UNIFOFMLY DISTRIBUTEO OVER THE AESCISSA RANG XMTN TO XMAX SONSISTENT WITH THE OATA-PCINT SDACTNG SELECTED. NOTE THAT THE DECIPROCAL DF THE DATA-POINT SPACI!!G PARAMETEO ENUALS THE PERCENTAGE OF DATA FOINTS TO EE PLOTTED.

AMPLITUCE CF ARFAY ER (OATAI IS FLOTTER IN DB BELOW MAYIMUM ARRAY VALUE. THE DB RANGE IS SPECIFIED TY YMINII) (MUST BE NEGATIVE)

PHASE OF ARRAY EZ IS PLOTIED IN REGEEER DETWEEN YMAX(2) AN YMINI2I

BOTH PHAS: AND AMP FLOTTEO ON SANE PLOT IF NO=2.

PHASE AND AMF PLCTTED SEPERATELY IE NO=1.

A USEG-SUPPLIEO 33-CHLEACTEP GRADH LAREL IS PFINTEO ON EACH PLO'. THIS CAPTION IS OQTAINEO EY REAOTNE ONE CAPTION CARD THE EIRST

TIME THE SUBPOUTINE IS CALLED. WHILE THE SAME 3O-CHARASTER LEGEND WILL SIMOLY BE USEC OVER AGAIN ON SUESERUENT CALLS TC THE ROUTINE ALSO, A TEN-CHARACTER USEE MESSAGE -FANNER- IS PQINTED ON EACH GDAPH, ALONG WITH THE MAXIMUM OB-LEVEL OF THE OATA AND A LOO GHARACTEO DESCRIFTION OF WHAT TYPE OF FRAFH IS BEING PLOTTED. THIS LATTER OISGRIDTION IS ORTAINED FROM THE PRESUHED TALLING SEQUENCE OF THE MAIN TPOGEAM, FAEEA. THE VALUE OF THE CONSTANT AZIMUTH O ELEVATION ANELE - ANGLE- FO THE GRAPH IS ALSO PQINTEO. A TOTAL LEGEND OF CO GHARACTEFS IS DFTNTED ON EACH GFADH.

USED SUFPLIES DIMMY AO ZAY DATA FOF INTEOMEDIATE STORAGE WHEN $M O D E=?$. TN HTS CASE, THE DIMENSION OF AREAY TATA EQUALS NZ $2 *$ F, WHEN MOCE 1 , THE INPU IS ASSUMED - O EE TH AREAY TATA AND ITS DIMENSION IS NZ=N.

DATA CARDS READ ON FIRST CALL TO SUREOUTYNE ONLY. FIRST INPU: CART.. NOO=NUMBEF DF CUDVES OFR GOADH 11 OP 21 XMTN, XMAX = SMALLEST AND GE TATEST ARSCISSA POINT YMIN(1) =AMOLITURE. FLO LOWEST OR VALUE $J=O O I N$ T SPACING BETWEEN DOJACENT PRINTED OATA VALUES. (IF JIS NONE OF THE DATA VALUES ARE DRINTEDI SUBROUTINE ALEO FE $\triangle D S$ A 3O-CHARACFE LEGENO CARD.

IF $(K .00 .3) \quad 13,14$

13 REAJ 99, NOO,XMIN, XMAX, YMIN(1), J

$14 Y I N(2)=3$. \$ YMAX(2) $=350$.

YMTN $(2)$ =PHASE DLOT SMALLFS? NUMOED OF DEGPEES (C.) YMAX(2) =PHASE PLOT LARGEST NUMRER OF DERREES (36?.)

IF (N2.LT. 2*N.AND. OOOE,EJ.2.OR.N2,LT.N.ANO,MONE.EO.1) 1.?

1 PFINT 104 CALL EXIT 
2 IF (XMAX,LE,XMIN.O ,YMIN(1), GE, . OOR,YMAX(2) .LE.YMIN(2)) 1, 3

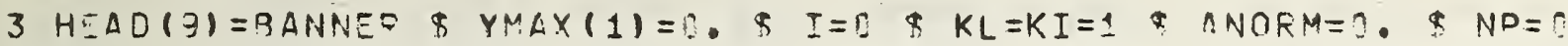
PEINT 1C5, NOO,XMIN, XMAX, YMIN(1), YMAX (1), YMTN(?), YMAX(?), PFINT 1C9, CAM(MODE)

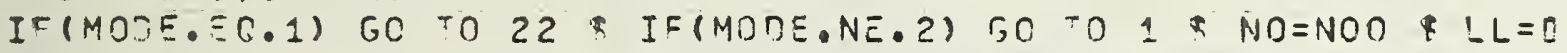

DO O $M=1, N$

IF (XVALUE (M).LE.XYIN) KI=M \& IF XXVLUE $(M), L E . X M A X) \quad K L=M$

OATA $(M)=C A B S(E R(M))$

IF $(D A T A(M), E Q .0 .14,5$

4 DATA $(M+N)=Y M I N(2) \$ 60$ TO 6

$5 I=I+1$

IF (DATA $(M)$, GT. ANOSM) ANCRM $=$ DAT $\triangle(M)$

$P=A T A M 2(A I M A G(E F(M)), R E A L 1=F(M)))$

IF (B.LT.J.) $B=B+6.2831853 J>179$

DATA $(M+N)=57.295779513082 * 0$

E CONT INUE

IF $(I, E 0.017,6$

.7 PINT $1: 6$ Gก TO 21

B $P=I N T 1:-$, ANDFM

IF (1.LE. O) 29.25

25 IF (J. $\equiv 7,1) \quad 2 E, 27$

$26 \quad I:=K I$ \& $I 2=K L \quad \$ N F=K L-K I+1 \$$ GO TO 28

$27 M=K L-K I+1 * L=(M-i) /$ ?

$N P=L / J$ \& $L=J^{*} N P$ \& $I 2=4 / 2+K I$ \& $I 1=I 2-L$ \& I2=I?+L \& $N P=?+N P+1$

28 IF (YO:E. $0_{0.1)} 3[, 31$

30 PFINT $113,(X V A L U E(M), D A T A(M), \because=I 1, I 2, J) \& 50$ in 29

31 PEINT 107, (XVALUE (M), DATA $(M), D A T A(M+N), M=I 1, J 2, J)$

29 ANOPM=2:. O* ALOG1: (ANODM)

ENCODE $(4 ?, 160$, SB) ANOPM, ELAZ(T Q), ANGLE, COMD (TA), COMP(IA+1)

OCCOOJ $(4 J, 1 L 1, B E) \quad(H-A D(M), M=1, L)$

DO $11 H=K I, K L$

IF $(O A: A(4), E 0.0 .19, \pm 0$

$9 D L T A(M)=Y M I A(:)$ \&O TO 11

10 DATA $(1)=2:$. * LLOG1C(DATA (H)) - ADOM

11 CENTINUE

IF (K. EQ.: $) 15,16$

$15 K= \pm$ PEAC $121,(H E A D(M), M=8,9)$

$16 \quad H=A \cap(Z)=A M F(?)$ \& $L=1$ \& $?=1 H$. \& $\quad I F(N C-2) \quad 13,1 ?, 1$

$17 P E I N T 122,(H E A C(M), M=1, ?)$

$18 H E A D(5)=A M P(L+L L) \& 3=1 H+$

$19 J E=(L-1) * N+K I$ \& $M=L$ \&F $(A O . E D . Z) \quad M=M O D(L, Z)+1$ \& $T 2=(M-1) * N+K I$

CALL SFTPLO: (XVALUE(KI),CATAI J), XNDX,XNIN,YA IX,YMIN,KL-KI+1,HEAD,

$X L, V O I$

CALL PLT12OP(XVALUE (KI), CATAII 2), XIA X, XYIN, YNAX $M$ ), YMIM (M),KL-KI+1

$Y, B, L, N O) \&$ IF (L. $\angle 0.2 .0=. M O D E .=0.1) 21,20$

$20 \mathrm{~L}=2 \& \mathrm{~B}=1 \mathrm{H}+\mathrm{IF}(\mathrm{NO}-1) 1,17,13$

21 FFINT 1:2, $(H E A O(M), M=1,3)$

PFINT $13, I . N D$

GC TO 32

22 Co $24 \quad M=1, M$

IF (XVRLUE(M).LE.XMIN) KI=N \& IF(XVALUE(A).LF.XMAX) $K L=M$

IF (DATA $(M) . E R .6)$.

$23 I=I+1$

IF (CATA (M) EET. ANOZM) $\triangle N C F M=D A^{-} A(M)$

24 CONTINUE

$N R=1 \$ L L=3$ \& IF (T.EN.?) 7,8

32 IF (HODE. E0.1) 33, T4

33 IP $=M O D(I B, 2)+1$ I $A=1$ \& GO TO $?=$

$34 I L=I A+2$

3E FETURN

EP:D 
SURPOUTINE PL-12RPX, Y, XNAX, XMIN, YMAX, YMTN, LAST, ISYMBOL, NOPLTI 1. MOSTI

250 CONTINUE

E. CONTINUE

PEINT 1E2:

PEINT 1537, $7 \times$

RETUPN 
SUPROUTENE CCFFT2(C,M,SC,NX)

DISCRETE COMPL:X FAST FOURI FR TRANSFOFM.

L. OAVIO LEWIS, NOAA-SEL, 730315

CALL CCFFT2 $(C, N, S C, N X)$

COMPLEX INPUT C(J) IN NDFMAL SEQUENCE.

COMPLEX OUTPUT C $(K)$ IN NCDיAL SFQUENCF.

SERUENCE LENGTH IS $N=2 * * M$

SC IS PEAL SCALING MULTIPLIED.

NX IS THE SIGN OF THE EXPONENT IN THE TNANSFOZM DEFINTTION.

USES CFFTPCD AND DEVBIND, n. V.

DIMENSION $C(2)$

CALL FEVBINO(C(1),C(?),M, 2$)$

CALL CFFTRCE $(C(1), C(2), M, S C, N X, 2)$

RETUF:I

ENO

SUPPOUTINE EEVBINT (A,R,NM,NOLL)

CALL REVPIND(A,F, Y,NO)

REVEESIBLE PEOYUTATICN OF 1 REAYS A ANC D

FPOM NORMAL SEDUENCE TO PEVERSE BINARY SEOUENCE,

OR. VICE VEFSA.

ND IS SUPSCRIP - INCFEMENT FOO A, 2 .

SEQUENCE LENGTH IS $N=2 * * 4$

WOITTEN EY L. OAVIO LFWIS AND MARIE WEST, ECSA.

MOJIFIED FDOM, OR INSPIFEN FY THE LLGCL PE ORERUEE

REVEFSEEINAEY,

DIMENSIDN A $(15384), B(15384)$

BY P. C. CP NGLFTON, CRI.

COMMON /FFTCC/ M, JD(15), ST(1E)

DIMENSION JC (15)

CALL OOLLCALL $148 H E / L 17:$

$M=M M$ \& CALL FFTC \& IF(N.LE.1) EEUYN

$N \cap=N O \equiv L$

OC $1 J, L C=1,1$ ?

$J C(L C)=J J(L C) \times N D$

$N=J C(N+1)-N D+1$ क $N P=N+1$

$K=1$ \& $I=N O+1$ \& $J=\because-N I$

$L r=M$

$K=K+J C(L C)+J C(L C)=-J C(L C)$

IF (JC(LC) ELT.N) GO TO 4

IF (LC. SD.2) FETUFN

$L C=L C-1 ; G 0 \div 0$ ?

IF (K.LE.I.OF.J.LT.K) GO TCE

$T=A(I) \& A(I)=A(K) \& A(K)=T$

$T=E(I) \quad B(I)=B(K) \quad B(K)=T$

IF $(J . \Sigma Q . K) \quad G O$ TO

$K K=N P-K$

$T=A(K K) \& A(K K)=A(J) \& A(J)=T$

$T=B(K K) ; B(K K)=B(J) \& B(J)=$ ?

$I=I+N O \& \quad J=J-N: D \& G C$ \&O 2

$\equiv N D$

SURROUTINE CFFTRCD $(A, B, M M, S C A L E, N E X F, N D=L)$

DISCDETE COMPLEX FAST FCURIER TRANSFOPM.

CALL CFFTPC.D (A, B, M, SC,NX,Nר)

OU-PITT $A(K)$ + I*B(K) IN NOPMAL SERUENEE.

ND IS SURSCRIF- INCREMENT ECO $\triangle$, P.

SENUENCE LENGTH IS $N=2 * * 4$

SC IS REAL SCALING MULTTPLT=?.

NX IS THE SIGN OF THE EXPONENT IN THE TEANGFOFM DEFINITION.

INNER LOOP SINES AND COSTNER CCMPUTEJ

RESUPSIVELY AY SINGLETOMES 2N[I-DIFFFE=NC= ALGNRI'HY,

IMITIALTZED FPCM A CATA TARLE. 


$$
K K=K S+J S P A N H
$$

IF (KK.LT.NLIM) GO TO $2 ?$

$$
\begin{aligned}
& K K=K K-N A \\
& J J=J J+K
\end{aligned}
$$

$86 K=K / 2$

IF (JJ.GE.NO) GO TO

$C D=P * C N+C D$

$C N=C D+C N$

$S^{N}=C N * E X P S$

$S D=2 * C^{M}+S D$

$S^{M}=S O+C M$

$S N=-C M * X P S$

GO TO 2:

90 CONTINUE

RETUON

ENC

SUBROUTINE FFTC

COMMOM SUBPOUTINE FOP FFT SUBRCUTINES.

JC IS POWEFS-OF-TWO AF FAY.. JO $(M)=2^{* *}(M-1)$

ST IS SINE $\triangle F F$ AY.. ST $(M)=S I_{N} N(P T /(2 * 7 M))$

1 IS TESTER FOE PFODEF INPUT PANGE, ?.LF.M.LE. 1 \&.

CCMMON /FFTCC/ M, JC $(15)$, Si $(13)$

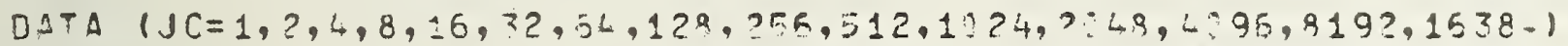

\section{DATA IST =}

1
2
3
4
5
6
7

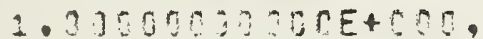

-.82E83L3? ZEEE-U1,

?. 91714 ? ? ?96E-4:2,

$2 .+541228-2 ? 9 E-42$.

$8.1358345-915 E-: 23$,

$1.53390 \div 18 E 20=-33$,

2. $23495187 \geqslant 71=-34$,

$0.5873799^{\circ}$ O. $50-(55)$

IF (M.LT. O.OOE.M.GT.1-) CALL CYOTEM $(32,13 H M$ TLLESAL.)

IF(M.LT.J.NF.M.GT.14) CALL NBO=RFCF (O,1 HM TLLFGAL.)

RETURN

END
7. $T 10 E ? 31187 E-001$,

1. $0=39 r 2 ? 2 \pi 16 E-001$

$4,0 ? 5 ? 6>43 ?>4 E-3 ? ?$,

1. ???1:3828 $375-3 j 2$,

3. $E>956>52 \square ? E-2: 3$,

-. $55000319743 E-204$,

1. $91747597311=-004$, 
Computer Program Modifications to obtain Theta and Phi Vector-Component Output Instead of Azimuth and Elevation Vector-Component Output

I. Required changes to VECTOR-COMPONENT-COMPUTATION section of program FAREA; replace DO loop, DO $33 \mathrm{M}-\mathrm{I1}$, I2 thru statement 33, with the following:

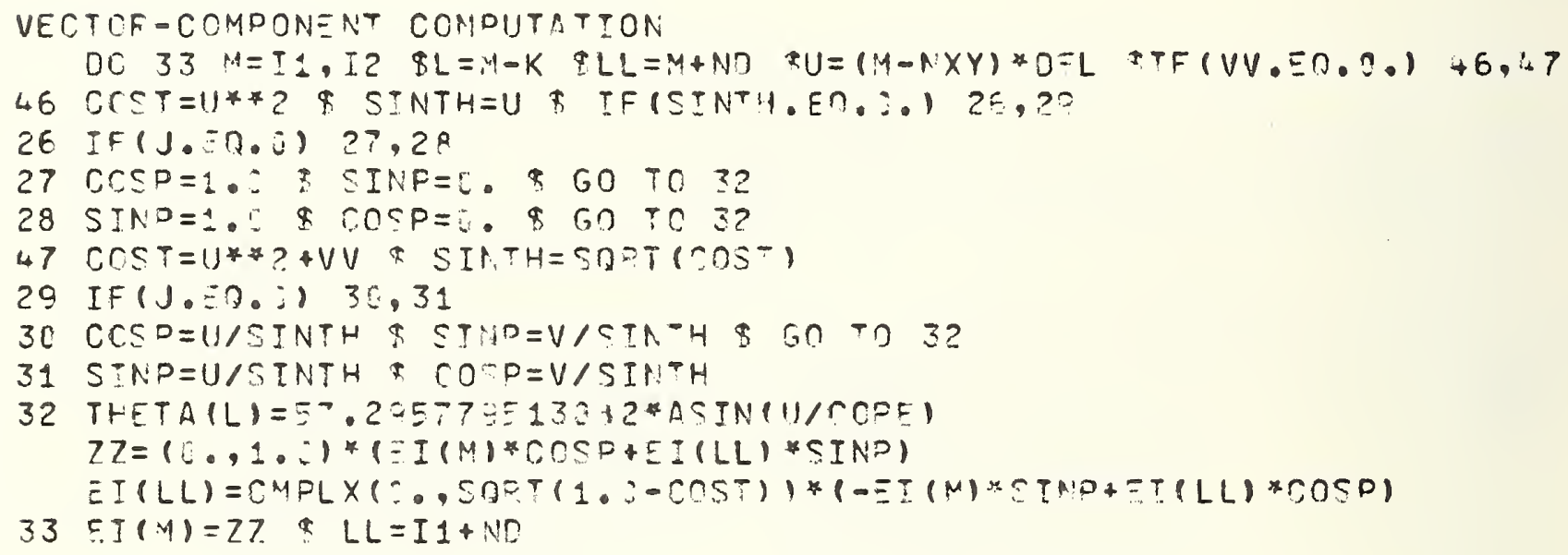

II. Subroutine PAMPLOT DATA-statement change; replace the first DATA statement card with the following:

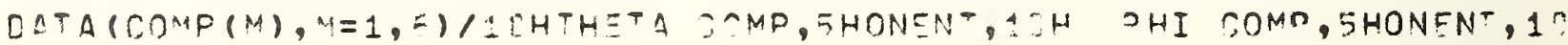




\section{Computer Program for Computing Principal-Plane-Cut Far Fields}

(This program ignores the jump change in sign of the electric-field vector when passing through the coordinate-system origin. Refer to equations (10) and (11) of Appendix A for details).

PROGRAM FARE (INPUT, OUTPUT, TAPE1 = I APUT)

DIMENSION STOR (1024), E(4096), THETA (1024), DATA (2048)

EQUIVALENCE (THETA, STOR)

COMPLEX STOR, E

DATA (NMAX $=1024)$, (NDIMEN=4096)

94 FORMAT $(4 F 7 \cdot 0,2 \times A 10,1 \times 2 I 2)$

95 FORMAT 1 1H1, 2X52HALPHA=X-COORDINATE APERTUKE DIMENSION IN WAVELENGT

THS, $9 \times 51$ HBETA=Y-COORDINATE APERTURE DIMENSION IN WAVELENGTHS/3X57HS UX $=R A T I O$ OF WAVELENGTH TO $X$-COORDINATE DATA-POINT SPACING, $4 X 57 H S Y=R$ VATIO OF WAVELENGTH TO Y-COORLINATE DATA-POINT SPACING/3X39HBANNER= W10-CHARACT $E R$ PLOT IDENTIFICATION, $4 X 39 H N Z X, N Z Y=Z E R O-F I L L ~ A R E A$ DOUBL $X I N G$ FACTORS, $4 X 44 H N N X, N N Y=N U M B E R$ OF TERMS IN $X$ - AND $Y$-FFT SUMS//18H $Y \quad A L F+A=, F O .3,4 X E H B E T A=, F 8.3,4 \times 4 \mathrm{HSX}=, F 7.3,4 \times 4 \mathrm{HSY}=, F 7.3,4 \times 7 \mathrm{HBANN}$ $Z E P,, A 10,1 \mathrm{H}, 14 \times 4 \mathrm{HNZX}=, I 2,3 \times 4 \mathrm{HNZY}=, I 2,7 \times 5 \mathrm{HNAX}=, I 5,4 \times 5 \mathrm{HNNY}=, I 5 / 11$

96 FORMAT 1 HO,25X37HAREAY DIMENSIONS TOO SMALL OR ILLEGAL//1X5HNNX =,

$A I 5,3 \times 20 H N N X=2 * M M X, M M X=, I 3,15 X 5 H N N Y=, I 5,3 \times 20 H N N Y=2 *$ MAY,

BMMY $=, I 3,15 \times 22 H C O M P U T E D$ E-DIMENSICN $=, I 6)$

97 FORMAT $(25 \times 5$ HMMX $=, I 3,25 \times 5$ HMMY $=, I 3 / 1)$

COMPUTATION OF THE FAR-FIELD PRINCIPAL-PLANE CUTS OF THE THETA- AND PHI-COMPONENTS OF THE ELECTRIC-FIELD VECTOR OUE TO A GIVEN NEAR-ZONE ELECTRIC-FIELD DISTRIBUTION IN A SPECIFIED AFEPTURE, ALONG WITH COMPUTATION OF THE FAR-FIELD PATTERNS FOR THESE PFINCIFAL-PLANE CUTS.

THE DATA SPACING BETWEEN $X$ - OR $Y$-COORDINATE ELEMENTS IS ASSUMED TO BE FIXED NMAX =OIMENSION OF AREAYS STOR AND THETA. DIMENSION OF ARRAY DATA SHCULD EQUAL 2*NMAX. NDIMEN IS THE CIMENSION OF ARRAY E. NDIMEN SHOULO EQUAL TWICE THE SUM OF THE $X$ - AND $Y$-FFT DIMENSIONS. THE MAXIMUM USEFUL VALUE OF NOIMEN IS 4 *NMAX.

INPUT PARAMETERS.

ALPHA=APERTURE WIDTH IN WAVELENGTHS (X-COORDINATE)

BETA=APERTURE LENGTH IN WAJELENGTHS (Y-COOROINATE)

$S X=R A T I O$ OF WAVELENGTH TO $X$-COOROINATE DATA-POINT SPACING SY=RATIC OF WAVELENGTH TO $Y$-COURCINATE DATA-POINT SPACING BANNER = 10-CHAFACTER G FAPH IOENTIFICATION

NZX $=$ NUMBER CF EXTR.A DOUBLINGS OF THE ZERO-FILL REGION FOR THE X-FAR-FIELD-CCORDINATE FFT. (NORMALLY $=1$ ) NZY $=$ NUMBER OF EXTKA DOUELINGS OF THE ZERO-FILL REGION FCR THE Y-FAF-FIELD-COORDINATE FFT. (NORMALLY=1)

THE INPUT DATA IS ASSUMED TO BE SUPPLIEO AS KOWS OF $X$-COOROINATE DATA, EACH WOW CORRESFONDING TO A FIXED VALUE OF THE Y-COOROINATE. ALL CF THE E-SUB-X DATA IS TO BE SUPPLIED FIRST, AND THEN THIS INPUT DATA IS TO BE FOLLOWEO BY ALL OF THE E-SUO-Y DATA. THE PROGRAM OBTAINS THE INPUT DATA THROUGH REPEATEO CALLS IO THE USER-SUFPLIED SUBROUTINE GETAFAY. 
EACH CALL TO SUBPOUTIN GETARAY RESUL-S IN A ROW OF NX AMPLEX OATA POINTS, FARH SLCRE SSIVE CALL CORRESOONDING TO A ROW

SUCCESCIVELY FURTHEF SELOW THE TOP AR THE ADEPTURE. HEO, NX IS ENUAL TO THE FFODUC ${ }^{-}$SX * ALPHA. THE NUMAEZ OF QOOWS. OO THE NUMBEF, OF CALLS TO GETARAY, IS PIYYAN BY NY = SY $*$ EETA.

NUMREF OF RATA CAFRS USFO BY PROGRAM+SURFOUTINES $=3$.

UPON CONPLETTNG A GTVIN SET OF FAR-FI=LO DRINCIPAL-PLANE COMPUTATIONS, THE COMDUTER PFOGPAM WTLL THEN PETUON TC THE BETINING DF THE FRTGRAN TO REAC A MEW TATA CAFI AND ST RT ALL OVEO AGAIN ON: A NEW FAF-FIELO COMOUTA ION. THTS TIME, HOWFVER, THE DLOT- ING ROUTINE PADAMETEES ANT LEGENC THAT WERE F=AD IN, OY THE FIRST TIME THEOUGH THAT SURPOU INF, $\triangle R E$ SIMPLY RECLLLFO $\triangle N O$ USTD CVER AGAIN. THE USFR MUST MAKE SURE SUBROUTINE GETARAY CAY SUPPLY $A$ WEW SET CF NOAF-FIELC DATA IIPON FESTARTING THF DOOGOAM.

PAFANETEP DEAD-IN!

1 PEAT QL ALOHA, BETA, SX, SY, BANNER, NTX, NTY

IF $(E O F(:)$. NE. O G GO TO 23

C CALCULATTON CF NX LNO NY

$N X=1 . * 5 *$ ALPHA $\$ N X=2 * N X+1$ \& $N Y=-.5 * S Y * Z=-4 * N Y=2 * N Y+1$

$S X=V X / A L P H A$ \& SY $=N Y / D E T A$

C CALCULATION OF NMIX A:O PMYY, RLCNG WITH MWX AN? WMY

$M Y X=M M Y=N N X=N N Y=1$

2 MAX $=M M X+1$ \& NNX $2^{*}$ NNX क IF(NNX.GT.NX) 3.2

$3 N N X=2$ *NNX \& IF $(N>X) \rightarrow \infty, \ldots, 2$

4 4 $N N X=N M X / 2$ \& $M M X=M X-1$; $60+0=$

$40 O E M=1, N Z X+M M X=M X+1$

$5 N M X=2^{*} N N X$

E. MMY MMNY I MMY

$7 N: Y=2 \times N N Y$ \& IF (N:TY) - $-1,2,8$

$45 \quad N: Y=N N Y / 2$ \& MNY MU:Y-1 \& 60 in 1?

8 Dr $g N=1, N Z Y$ * $M M Y M N Y+1$

9 NAY $=2 * N H Y$

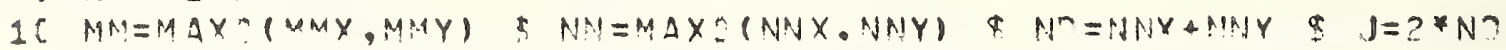

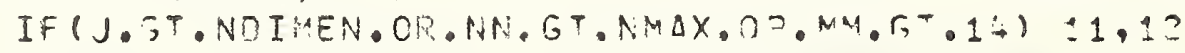

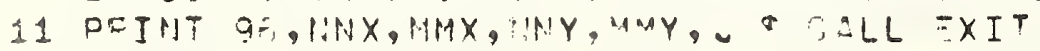

C INFUT PATA"TET FRTN-OUT

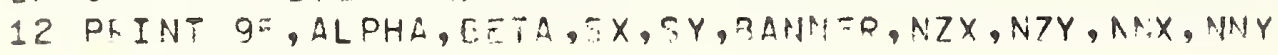

DEINT $9^{7, M M X, M M Y ~}$

COMPUTATION OF AFEFTUFE CATA-OCIUT SDACINGE

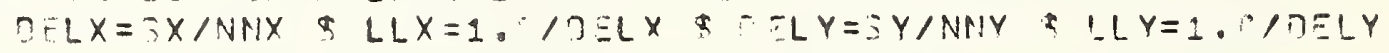

C COMFUTATIOH OF AEERTURE-IATA POSTTTON WITHTN -HE TV EGPATION INTESVAL

FLCTOP=1. $/\left(S X^{*} S Y\right)$ \& I $X X=(N N X-N X+1) / 2$ \& IIY=(NINY-NY+1)/ZRNNX

PRE-ZEROINT, CF INTEGOAL FIELC

[C $13 \quad 4=1, J$

$13 \equiv(\mu)=\left(B, C_{0}\right)$

C DO LOCP T O COMPUTE TWO PLANEORUT INTEGOALS CVOE AOEOTURE-FIELO VETTOP

on $25 I=1,2$ \& $M X=110 *(T-1)$ a $I X=M X+I X$ \& $I Y=\mu X+T: Y$

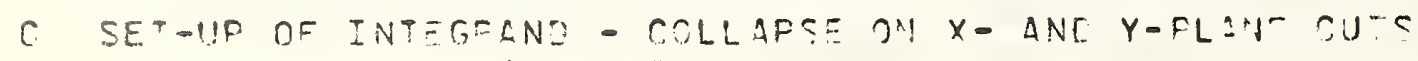

DC $14 K=1, N Y$ \& $J=K+I Y$ 
CALL DEYAPAY RTCP,NX)

OO 1 is $L=1, N X \quad N=L+T X$

$E(M)=-(M)+C+0=(L)$

$14 E(J)=\because(J)+S T O R(L)$

INITIALIZE Y-PLANEE-CUT DAOANCT=OC

$N X Y=N X \& M M=M M X$ \& $N M=N N X$ \& $n E L=7 F L X \& L L=L L X$

FACTO $==-F A C T O F$ \& $J=:$

15. $N M I D=N N / 2+1$ \& I2 $=I X+N X Y \quad I I=Z X+1$ \& IF $(M O D(N X Y / 2,2) .50 .0) \quad I 1=I:+1$

PRE-FFT AULTIPLICATION $=Y \quad(-1) * * 4$

DC, $16 M=I 1, T 2,2$

$16 E(M)=-E(M)$

FFT COMPUTATION

CALL CCFFT2(E $(M X+1), M M, F A C T \cap=,-1)$

$I:=1 X+2 \quad I Z=M X+N N \& J J=M C ?(J+T-1,2)$

POST -FFT MIJLIPLICATION RY $(-1) * 3$

CO $17 M=I \pm, T 2,2$

$17 E(M)=-E(M)$

RESTEICT COMPUTATIONS TO Z ZAL POLAO SPATIAL-FOENUEMTY ANTLES

IF (LL.G $\left.G^{\top}, N M I D-2\right) \quad 18,19$

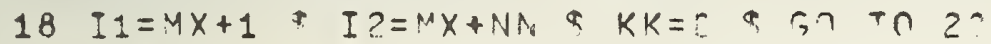

$19 K K=N M I J-L L \& I 1=K K+M X$ \& $I ?=I 1+? * L L \& K K=K K-1$

20 NMIO $=N M I T+N X \times K=K K+! X$

VECTCF-COMPONENT COMFUTATION

DO $23 \quad M=I A, I 2 \$ L=M-K$ \& $L L=M-K K$

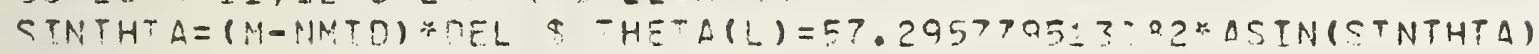

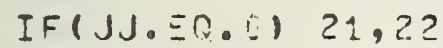

$21 E(L L)=(\ldots 1,1 * C(*)+G 0-0 \geq 2$

$22 E(L L)=C M P L X(5, S \cap \div(1 .:-5 I N T H-B * 2)) * E(*)$

23 CENTINUE

VECTOF-COMFONENT PLO-TING,

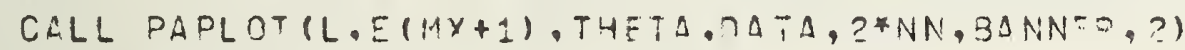

IF (J. $: 0.0) \quad 24,25$

INITIALIZE X-PLANE-CIT DADANETEO

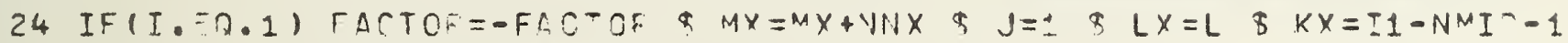

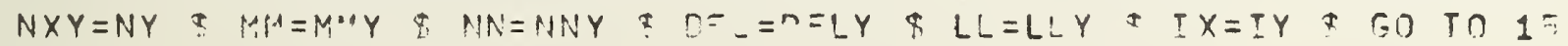

$25 L Y=L$

$I:=N N X+: T Z=H A N X+L Y$

ANTENNA -PAT EON COMPIJTATION

DC $2 \in \quad M=I 1, I 2$ \& $J=M+M$ D

26 OLTA $(1)=S Q F T(\div \equiv A L(E(N) * C C N J G(-(M))+E(J) * C O N J T(=(1)) 1)$

ANTEPNA-PATTERM PLOTIING (X-PLANE CU $\left.{ }^{\top}\right)$

CALL PAPLOT (LY, C. THFTA, CATA II1),LY, BANNER.1)

OC $27 \quad M=1, L X$ \& $J=11+N O$

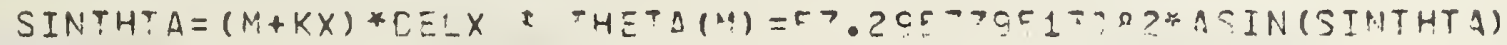

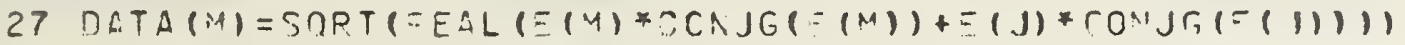

C ANTEANA-DATTEFN FLOT:INS (Y-FLAN= C,IT)

CDLL DAPLOT $(L X, Z, T H E T A, D F T, L X, P \triangle N N E=, 1)$

GC TO 1

28 ECNTIYUV

ENC 
Appendix D: Modifications to subroutine PAMPLOT for compatibility with principal-plane-cut program.

I. SUBROUTINE name change and SUBROUTINE argument-1ist change:

SURROUTINE PAPLOT (N, EO, XVALUE, 2ATA, N2, EANNE=, MOOE)

II. Subroutine DATA-statement change:

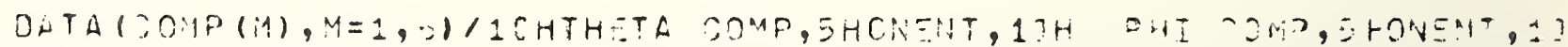

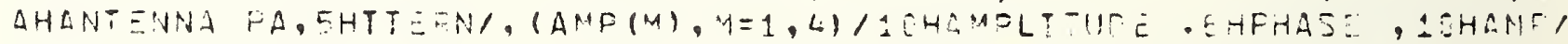
BPHASE, IIMMAGIITUEE /, (ELAT(M),M=1,2)/QH PHT = E,,$H=H T=F T / 2 /$

III. FORMAT-statement change and change in ENCODE statement (the latter statement is located just following statement 29):

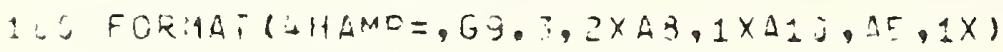

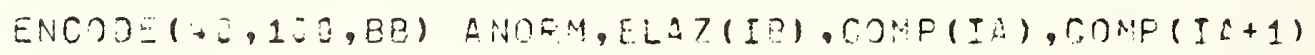

IV. Replace statements 32 thru 35 (located at end of subroutine) with the following six statements:

32 IF (IA. In, 1) 33,36

33 IF $(I 3.50 .1) \quad 34,35$

34 I $A=3$ \& $19=2+60$ I 0 ?

35 IL $=5$ क 60 TO 37

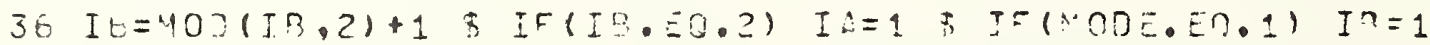

37 RT TURN 


